\title{
Longitudinal Assessment of Gray and White Matter in Chronic Schizophrenia: A Combined Diffusion-Tensor and Structural Magnetic Resonance Imaging Study
}

\author{
Serge A. Mitelman ${ }^{1, *}$, Emily L. Canfield ${ }^{1}$, Randall E. Newmark ${ }^{1}$, Adam M. Brickman ${ }^{2}$, \\ Yuliya Torosjan ${ }^{1}$, King-Wai Chu ${ }^{1}$, Erin A. Hazlett ${ }^{1}$, M. Mehmet Haznedar ${ }^{1}$, Lina Shihabuddin ${ }^{1}$ and \\ Monte S. Buchsbaum ${ }^{3}$ \\ ${ }^{I}$ Department of Psychiatry, Mount Sinai School of Medicine, New York, USA \\ ${ }^{2}$ Department of Psychiatry, Columbia University College of Physicians and Surgeons, New York, USA \\ ${ }^{3}$ Departments of Psychiatry and Radiology, University of California, San Diego, USA
}

\begin{abstract}
Previous studies have reported continued focal gray matter loss after the clinical onset of schizophrenia. Longitudinal assessments in chronic illness, of white matter in particular, have been less conclusive.

We used diffusion-tensor and structural magnetic resonance imaging in 16 healthy subjects and 49 chronic schizophrenia patients, subdivided into good-outcome $(n=23)$ and poor-outcome $(n=26)$ groups, scanned twice 4 years apart. Fractional anisotropy, gray matter and white matter volumes were parcellated into the Brodmann's areas and entered into multiway ANCOVAs.

At baseline, schizophrenia patients had 1) lower anisotropy in frontoparietal white matter, 2) larger posterior frontal white matter volumes, and 3) smaller frontal, temporal, and parietal gray matter volumes. On follow-up, healthy subjects showed a more pronounced 1) decline in anisotropy, 2) expansion of regional white matter volumes, and 3) reduction in regional gray matter volumes than schizophrenia patients. Good-outcome patients showed a more pronounced decline in white matter anisotropy and a less pronounced increase in white matter volumes than poor-outcome patients. Poor-outcome patients displayed a greater gray matter loss throughout the brain than good-outcome patients.

In the chronic phase of the illness, longitudinal changes in both gray and white matter are in the direction of an effacement of between-group differences among schizophrenia patients and healthy subjects. Similarly, preexisting white matter differences between good-outcome and poor-outcome patients diminish over time. In contrast, gray matter volumes in poor-outcome patients continue to decline more rapidly than in patients with good outcome. These patterns are consistent with earlier onset of aging-associated changes in schizophrenia.
\end{abstract}

Key Words: Kraepelinian schizophrenia, poor outcome, anisotropy, white matter, illness progression.

\section{INTRODUCTION}

Illness progression remains a debated topic in schizophrenia neuroimaging research $[1,2]$. It has been convincingly demonstrated that there is a continuing loss of gray matter volume for a period of perhaps several years leading to and immediately following the first outbreak of psychotic symptoms (reviewed in $[3,4]$ ). Yet, further changes in gray matter and the white matter dynamics over the later course of the illness are not as well understood. Although some authors reported a similarly progressive decline in gray matter volumes in chronic schizophrenia patients as had been shown after the first psychotic outbreak [5], the interpretation of these results gained a degree of controversy when

*Address correspondence to this author at the Mount Sinai Medical Center, Department of Psychiatry, Box 1505, Neuroscience Positron Emission Tomography Laboratory, One Gustave L. Levy Place, New York, New York 10029, USA; Tel: 1 (212) 241-5294; Fax: 1 (212) 423-0819;

E-mail: serge.mitelman@mssm.edu
Weinberger and McClure [6] proposed that these findings in fact may be epiphenomenal, reflecting the methodological and/or physiological vicissitudes rather than a true tissue loss. This claim sprang from a rather obvious conjecture that by extrapolating the reported rate of excessive gray matter loss early in the illness (2-7\% per year in various studies) in due time schizophrenia patients risk being left void of gray matter altogether. The possibility of a nonlinear volumetric change with age in patients with schizophrenia had been largely dismissed in the authors' initial argumentation as was already pointed out by Mathalon et al. [7] in their earliest response to the criticisms of Weinberger and McClure. A more recent review of the still rare longitudinal MRI studies in chronic schizophrenia patients, however, concludes that this indeed may be the case and that, unlike normal aging, the rate of regional changes in both gray and white matter volumes in patients with schizophrenia slows down with age [8].

Brain tissue changes during the course of normal aging include decline in gray matter volumes and corresponding 
increase in white matter volumes, but the timeframes of these changes are different for each tissue type (reviewed in $[9,10])$. Thus, while gray matter loss with age follows a linear course, longitudinal white matter volume changes follow a reversed U-curve, expanding through the fifth decade of life and shrinking in the later years $[11,12]$. Further, Bartzokis et al. point to a differential lobar topography of the longitudinal white matter dynamics: the volumes peak at age 44.6 years in the frontal lobe and at the age of 47 years in the temporal lobe [11]. Fractional anisotropy in the white matter shows similar but more linear anteroposterior dynamics (see [13] for review). Thus, while global white matter fractional anisotropy decreases with age [14], frontal regions appear to be affected first, followed by the temporal regions with sparing of the parietal and occipital lobes [15]. There is a suggestion that changes in fractional anisotropy precede coterritorial and apparently correlated volumetric changes in normal aging, hence may represent a more sensitive index of white matter aging [16-18].

Many longitudinal studies have recorded progressive decline in frontotemporal gray matter volumes in patients with schizophrenia over time. The vast majority of these studies, however, have specifically focused on the adolescent or young adult first-episode schizophrenia patients for a period of time up to 5 years following the symptomatic onset of the disease [19-30]. Longitudinal assessments in more chronic patients have been relatively few and less conclusive: one reporting significant volume loss [5], another focal gray matter density loss [31], and 3 others - no progressive changes [32-34]. van Haren et al. [35], by studying a longitudinal cohort of schizophrenia patients aged 16 to 56 years, divided into subgroups based on the duration of illness, conclude that progressive gray matter volume loss in excess of normal aging slows down with age and is discernable only up to approximately 45 years of age (or 20 years into the illness); this volume loss is more pronounced in patients with poor clinical outcome. Still scanter are the longitudinal assessments of white matter volumes in schizophrenia. Ho et al. [23] documented reductions in the frontal white matter and Whitford et al. [36] in the posterior temporal white matter volumes over the 3-year period following the first psychotic outbreak. van Haren et al. in the above-cited study [35] report that white matter volumes in their patients were expanding with age at an ever-slowing rate until the expansion was no longer detectable by the age of 51 years. Finally, no longitudinal follow-up reports of the white matter anisotropy changes in patients with schizophrenia have yet been published, but two cross-sectional studies [37, 38] conclude that widespread decreases in fractional anisotropy with age are more pronounced in schizophrenia and are related to the duration of illness.

The goal of the present study was to investigate the progression of changes in gray and white matter volumes, as well as white matter fractional anisotropy, in a group of middle-aged patients with chronic schizophrenia. We strived to determine whether the illness remains uniformly progressive in its chronic phase (as it appears to be around the first psychotic outbreak) and hypothesized that the morphometric evidence of the illness progression will only be evident in the more severe schizophrenia patients with poor clinical outcome. To this end, patients were divided into those with good and poor outcomes and an identical parcellation scheme was applied to both gray and white matter. This approach has previously been used in our cross-sectional studies on the large original sample which served as the recruitment base for the present follow-up [39-41], thus providing directly comparable longitudinal data.

\section{MATERIALS AND METHODOLOGY}

\section{Subjects \\ Follow-up Sample}

The follow-up cohort comprised 49 patients with schizophrenia (age at baseline scan $42.69 \pm 12.29$ years; 7 women; 2 left-handed) and 16 healthy subjects (age at baseline $41.63 \pm 12.23$ years, $\mathrm{t}_{63}=0.30, \mathrm{p}=\mathrm{ns} ; 7$ women; no lefthanded), scanned approximately 4 years apart $(4.10 \pm 0.54$ years for schizophrenia patients and $4.22 \pm 0.52$ years for healthy subjects, $\left.\mathrm{t}_{63}=0.76, \mathrm{p}=\mathrm{ns}\right)$. Schizophrenia patients had significantly lower baseline Mini-Mental State Examination (MMSE) scores than healthy subjects $\left(\mathrm{t}_{56}=4.17, \mathrm{p}=0.0001\right)$, but did not significantly differ in major demographic characteristics (Table 1). These 65 participants underwent morphometric analyses for regional gray and white matter volumes. A smaller sample of 49 participants was available for the diffusion-tensor imaging (DTI) analyses: this DTI sample comprised 13 healthy subjects and 34 schizophrenia patients (17 with good outcome and 17 with poor outcome). All participants were administered a semi-structured diagnostic interview with the Comprehensive Assessment of Symptoms and History [42]. Patients with schizophrenia were recruited from the inpatient and outpatient services at Pilgrim State Psychiatric Center, Mount Sinai and Bronx VA Medical Centers, - all in New York metropolitan area. The matched normal comparison subjects were recruited through advertisement. The exclusion criteria comprised a history of substance abuse, head trauma, neurological illness, average body weight that exceeded upper $25^{\text {th }}$ percentile, significant abnormalities on screening physical examination and laboratory tests (including urine toxicology screen, thyroid function, VDRL, $\mathrm{B}_{12}$ and folate levels). The project was approved by the institutional review board of the Mount Sinai School of Medicine and informed consent was obtained from each participant.

Patients with schizophrenia were classified into the goodoutcome $(n=23)$ and poor-outcome $(n=26)$ subgroups based on the criteria by Keefe et al. [43, 44]. In brief, these required that poor-outcome patients met the following criteria for at least five years prior to study contact: 1) continuous hospitalization or complete dependence on others for food, clothing, and shelter; 2) no useful employment; and 3) no evidence of symptom remission. All other schizophrenia patients were considered good-outcome. Patients classified as poor-outcome (age 47.35 \pm 11.9 years; 1 woman) were significantly older at baseline scan than patients with good outcome $\left(37.44 \pm 10.68\right.$ years, $\mathrm{t}_{47}=3.05, \mathrm{p}=0.004 ; 6$ women $)$, but did not differ in length of between-scan interval (3.98 \pm 0.4 years vs. $4.24 \pm 0.65$ years, respectively, $\mathrm{t}_{47}=1.76$, $\mathrm{p}=0.09$ ). PANSS assessments at baseline showed that patients with poor outcome, as compared to those with good outcome, had significantly more severe positive $(22.4 \pm 6.64$ vs. $\left.15.39 \pm 4.92, \mathrm{t}_{47}=4.12, \mathrm{p}=0.00015\right)$, negative $(22.36 \pm 7.40$ 
Table 1. Clinical and Demographic Characteristics

\begin{tabular}{|c|c|c|c|c|c|c|c|}
\hline Subject Group & Age at Initial Scan Date & Age at First Treatment ${ }^{\mathrm{a}}$ & Duration of Illness $^{b}$ & & PANSS $^{\mathrm{c}}$ & & MMSE $^{\mathrm{d}}$ \\
\hline & & & & Positive & Negative & General & \\
\hline \multicolumn{8}{|c|}{ FULL BASELINE SAMPLE $(\mathrm{n}=145)$} \\
\hline Healthy Subjects $(n=41)$ & $44.15 \pm 14.66$ & & & & & & $29.86 \pm 9.12$ \\
\hline Schizophrenia Patients (n=104) & $42.77 \pm 12.12$ & $24.96 \pm 9.12$ & $18.49 \pm 12.71$ & $18.86 \pm 6.64$ & $18.91 \pm 7.77$ & $37.07 \pm 9.87$ & $26.86 \pm 2.71$ \\
\hline Good-Outcome Patients ( $\mathrm{n}=51$ ) & $40.62 \pm 12.60$ & $26.82 \pm 7.06$ & $14.82 \pm 12.10$ & $16.04 \pm 4.94$ & $16.25 \pm 5.53$ & $32.38 \pm 7.83$ & $27.00 \pm 2.64$ \\
\hline Poor-Outcome Patients $(\mathrm{n}=53)$ & $44.79 \pm 11.39$ & $22.82 \pm 10.74$ & $22.74 \pm 12.20$ & $21.74 \pm 6.94$ & $21.60 \pm 8.72$ & $41.81 \pm 9.42$ & $26.72 \pm 2.80$ \\
\hline \multicolumn{8}{|l|}{ FOLLOW-UP COHORT $(\mathrm{n}=65)$} \\
\hline Healthy Subjects $(\mathrm{n}=16)$ & $41.62 \pm 12.23$ & & & & & & $30.00 \pm 0.00$ \\
\hline Schizophrenia Patients $(n=49)$ & $42.69 \pm 12.29$ & $23.80 \pm 8.01$ & $18.67 \pm 12.05$ & $19.04 \pm 6.80$ & $19.00 \pm 7.25$ & $40.53 \pm 13.23$ & $26.47 \pm 3.15$ \\
\hline Good-Outcome Patients (n=23) & $37.44 \pm 10.68$ & $26.81 \pm 5.51$ & $12.29 \pm 8.78$ & $15.39 \pm 4.92$ & $15.35 \pm 5.08$ & $35.32 \pm 14.63$ & $27.32 \pm 2.36$ \\
\hline Poor-Outcome Patients (n=26) & $47.35 \pm 11.90$ & $20.96 \pm 9.05$ & $24.77 \pm 11.71$ & $22.4 \pm 6.64$ & $22.36 \pm 7.40$ & $45.12 \pm 10.05$ & $25.79 \pm 3.56$ \\
\hline \multicolumn{8}{|l|}{ DROP-OUT SAMPLE (n=80) } \\
\hline Healthy Subjects $(\mathrm{n}=25)$ & $45.62 \pm 15.75$ & & & & & & $29.77 \pm 0.53$ \\
\hline Schizophrenia Patients $(\mathrm{n}=55)$ & $43.19 \pm 12.37$ & $25.38 \pm 9.88$ & $18.40 \pm 13.08$ & $18.38 \pm 6.20$ & $19.00 \pm 8.46$ & $35.52 \pm 10.14$ & $27.20 \pm 2.43$ \\
\hline Good-Outcome Patients $(\mathrm{n}=28)$ & $42.21 \pm 13.25$ & $26.46 \pm 8.10$ & $16.54 \pm 13.66$ & $16.96 \pm 5.53$ & $16.52 \pm 5.98$ & $33.27 \pm 7.83$ & $27.36 \pm 2.08$ \\
\hline Poor-Outcome Patients $(n=27)$ & $43.62 \pm 11.53$ & $23.90 \pm 11.98$ & $20.95 \pm 12.12$ & $20.36 \pm 6.63$ & $21.23 \pm 9.87$ & $40.04 \pm 8.86$ & $27.35 \pm 2.41$ \\
\hline
\end{tabular}

${ }^{\mathrm{a}}$ Documented age at the time of first exposure to antipsychotic agents

${ }^{\mathrm{b}}$ Time (in years) since the first illness-related exposure to antipsychotic agents to the initial scan

${ }^{\mathrm{c}}$ Positive and Negative Syndrome Scale

${ }^{\mathrm{d}}$ Mini-Mental State Examination.

vs. $\left.15.35 \pm 5.08, \mathrm{t}_{47}=3.79, \mathrm{p}=0.0004\right)$, and general psychopathology scores $\left(45.12 \pm 10.05\right.$ vs. $35.32 \pm 14.63, \mathrm{t}_{47}=2.7$, $\mathrm{p}=0.01)$, as well as a longer duration of illness $\left(\mathrm{t}_{41}=3.94\right.$, $\mathrm{p}=0.0003$ ), but did not differ significantly in MMSE scores $(t=1.6, p=0.12)$. Duration of illness at the initial scan date was conservatively constructed as time in years since the age of the first illness-related antipsychotic treatment.

\section{Comparison with Full Baseline Sample and with Subjects Lost to Follow-up}

This follow-up cohort of 65 subjects was recruited as a 4year continuation of our baseline study of 104 patients with schizophrenia (51 with good outcome and 53 with poor outcome) and 41 healthy subjects, published elsewhere [39-41, 45-51]. In order to rule out potential sources of systematic bias in subject retention and attrition, we compared age and illness severity of the current follow-up cohort with those of the full baseline sample of 145 participants and with those of the drop-outs that were lost to 4-year follow-up (Table 1). There were no significant differences in age or PANSS subscale scores between healthy subjects, all schizophrenia patients, and schizophrenia subgroups by outcome in the comparison of the full original sample of 145 participants and the current follow-up cohort of 65 participants. There was a trend $\left(\mathrm{t}_{151}=1.65, \mathrm{p}=0.073\right)$ towards more severe general psychopathology PANSS subscale score in schizophrenia patients in the current follow-up cohort $(40.53 \pm 13.23)$ than in the full original sample (37.07 \pm 9.87$)$.

In the comparison of the current follow-up cohort of 65 subjects with the drop-out sample of 80 subjects, schizophrenia patients retained to follow-up $(n=49)$ had signifi- cantly more severe $\left(\mathrm{t}_{102}=2.36, \mathrm{p}=0.032\right)$ PANSS general psychopathology scores $(40.53 \pm 13.23)$ than schizophrenia patients that were lost to follow-up $(n=55,35.52 \pm 10.14)$. There was also a trend towards more severe PANSS general psychopathology scores $\left(\mathrm{t}_{51}=2.01, \mathrm{p}=0.056\right)$ in the pooroutcome schizophrenia patients that were retained for follow-up $(n=26,45.12 \pm 10.05)$ than in the poor-outcome patients that were lost to follow-up $(n=27,40.04 \pm 8.86)$. The healthy subjects, all schizophrenia patients, good-outcome and poor-outcome subgroups in the current follow-up and the drop-out samples were not significantly different otherwise.

\section{Image Acquisition and Processing}

$\mathrm{T}_{1}$-weighted $\mathrm{MR}$ images were acquired using a $1.5 \mathrm{~T}$ Signa $5 \times$ scanner (GE Medical Systems) with a 3D-SPGR sequence $\left(\mathrm{TR}=24 \mathrm{msec}, \mathrm{TE}=5 \mathrm{msec}\right.$, flip angle $=40^{\circ}$, matrix size $256 \times 256$, field of view $23 \mathrm{~cm}$, slice thickness $1.2 \mathrm{~mm}$, total slices $128, \mathrm{NEX}=1$ ). The diffusion tensor sequence acquired fourteen 7.5-mm-thick slices $(\mathrm{TR}=10 \mathrm{~s}, \mathrm{TE}=99$ $\mathrm{ms}, \mathrm{TI}=2.2 \mathrm{~s}, \mathrm{~b}=750 \mathrm{~s} / \mathrm{mm}, \delta=31 \mathrm{~ms}, \Delta=73 \mathrm{~ms})$. Before the diffusion EPI sequence, a Turbo Spin Echo was also acquired to obtain a localizing anatomical image. In order to solve for the components of the diffusion tensor, seven diffusion EPI images were obtained: six with different noncollinear gradient weightings and one with no diffusion gradient applied. The diffusion tensor for every voxel in a slice was then computed by solving the seven simultaneous signal equations relating the measured signal intensity to the diffusion tensor. Anatomical SPGR MR images were resectioned to standard Talairach-Tournoux position using the 
algorithm of Woods et al. [52] and a 6-parameter rigid-body transformation. The anisotropy images from each subject were then aligned to subject's own standard-position anatomical images using the same 6-parameter rigid-body transformation. We computed the eigenvectors and eigenvalues for every tensor, which created the basic raw dataset for subsequent analyses. The eigenvector associated with the largest eigenvalue, or principal diffusivity, indicates the direction of the maximal apparent diffusivity, which in normal white matter corresponds to the orientation of the axis of an axonal bundle.

\section{Brodmann's Area Analysis}

Brodmann map parcellation and quantification of tissue types were performed exactly as in our previous reports on the full baseline sample, from which the present longitudinal cohort was drawn (cf. [47]). Briefly, we used a semiautomated parcellation technique based on the Perry postmortem brain atlas (the atlas was published in [47]). This method splits manually traced coronal brain slices into 20 radial and 10 midline sectors in each hemisphere, and each temporal lobe into 16 sectors, which are then assigned to 40 Brodmann's areas identified in the Perry atlas. Segmentation into the white and gray tissue types is done using the FSL program FAST with bias field correction of MRIs followed by kmeans clustering and local Markov analysis at each voxel; a binary image is created for each of the tissue types, which has received extensive methodological examination [53]. Note that in this study fractional anisotropy was averaged across white matter regions underlying cortical Brodmann's areas and was thus treated as general tissue property with no reference to particular white matter tracts. This averaging allows for between-group comparisons of the rates of longitudinal changes in regional white matter integrity. Similarly, quantifying regional white matter volumes in reference to cortical Brodmann's areas allows the betweengroup differences in longitudinal volume change to be regionally delineated.

\section{Statistical Analyses}

In this study, we utilized a strategy used in our previous publications on the full baseline sample of patients with good and poor outcome schizophrenia (cf. [41]). The goal was to demonstrate significant differences in overall patterns of changes in regional tissue volumes and anisotropy between diagnostic groups over time using ANOVA for lobar constellations of Brodmann's areas and then to further localize the differences by using follow-up $t$ tests for between-group comparisons of individual Brodmann's areas. Separate analyses of variance were thus performed for the cingulate gyrus, frontal, temporal, parietal, and occipital lobes. Then, in order to describe a prevailing overall pattern of between-group differences we contrasted frontal, temporal, and parietal lobes (each comprising 11 Brodmann's areas) in a single analysis (see Tables 2, 3, 4 and $\mathbf{5}$ for groupings of individual Brodmann's areas in regional contrasts).

Since there were significant differences in age among patients with different outcomes in our cohort, we employed ANCOVA with age at initial scan and length of the interval between the baseline and follow-up scans as covariates. There also were significant differences in illness duration among the two patient groups (as conservatively judged by years between the first exposure to neuroleptic treatment and initial MRI scan), which is known to be associated with lower gray matter volumes $[54,55]$. We therefore ran ANCOVAs controlling for all 3 potential sources of systematic bias (illness duration, age at first scan and interscan interval). Since illness duration was not available for 5 patients, we tabulate both analyses (with and without illness duration as covariate) and comment on the differential results in the text. All analyses were performed for both absolute and relative tissue volumes, with very similar results. Absolute gray and white matter volumes for each Brodmann's area were divided by total brain gray and white matter volume respectively to convert them into relative volumetric data. Similarly, in order to correct for any potential variation over time, average fractional anisotropy values for each Brodmann's area were divided by the average fractional anisotropy value of the whole-brain white matter, which yielded relative fractional anisotropy values used in the current analyses.

In order to put the longitudinal data in proper perspective, we analyzed baseline between-group differences in volumes and anisotropy first. For analyses of between-group differences in tissue volumes and anisotropy at baseline, we entered relative gray matter volume, white matter volume or fractional anisotropy values into a three-way ANCOVA (age as covariate) with independent diagnostic groups (schizophrenia patients and healthy subjects or good-outcome and poor-outcome patients) and repeated measures for hemisphere (left and right), specific Brodmann's areas within each region (e.g. 23, 24, 25, 26, 29, 30, 31, 32 for the cingulate gyrus). For longitudinal analyses, we entered gray matter volume, white matter volume, or fractional anisotropy values into a 4-way ANCOVA with independent diagnostic groups (schizophrenia patients and healthy subjects or goodoutcome and poor-outcome patients) and repeated measures for time (baseline and follow-up scans), hemisphere (left and right), specific Brodmann's areas within each analyzed region (e.g. 20, 21, 22, 27, 28, 34, 35, 36, 37, 38, 41, 42 for the temporal lobe analysis). For an overall contrast of the frontal, temporal, and parietal lobes, as well as a contrast of the medial and lateral temporal regions, a 5-way ANCOVA was used with independent diagnostic groups (schizophrenia patients and healthy subjects or good-outcome and pooroutcome patients) and repeated measures for time (baseline and follow-up scans), hemisphere (left and right), region (frontal, temporal, and parietal; or medial temporal and lateral temporal), Brodmann's areas within each region (e.g. 4, 6, 8, 9, 10, 11, 12, 44, 45, 46, 47 for the frontal lobe). Significant diagnostic group by time and higher-order (group by time by Brodmann's area, group by time by hemisphere by Brodmann's area) interactions were documented, each significant interaction was subjected to the Huynh-Feldt procedure for degree-of-freedom correction and graphs were examined for any discernable patterns of differential longitudinal changes, - all described in the results section.

Note that Brodmann's areas 1, 2, 3, and 5 were combined into a single area (1-2-3-5) in our analyses because of the difficulties in their individual parcellation. Follow-up Student's t tests were done for baseline minus follow-up volumetric and anisotropy values (difference scores) for individual Brodmann's areas to localize the sources of significant ANCOVA interactions within each Brodmann's 
Table 2. Significant ANCOVA Interactions for Between-Group Differences in Relative Gray Matter Volumes, Relative White Matter Volumes, and Fractional Anisotropy at Baseline Scan

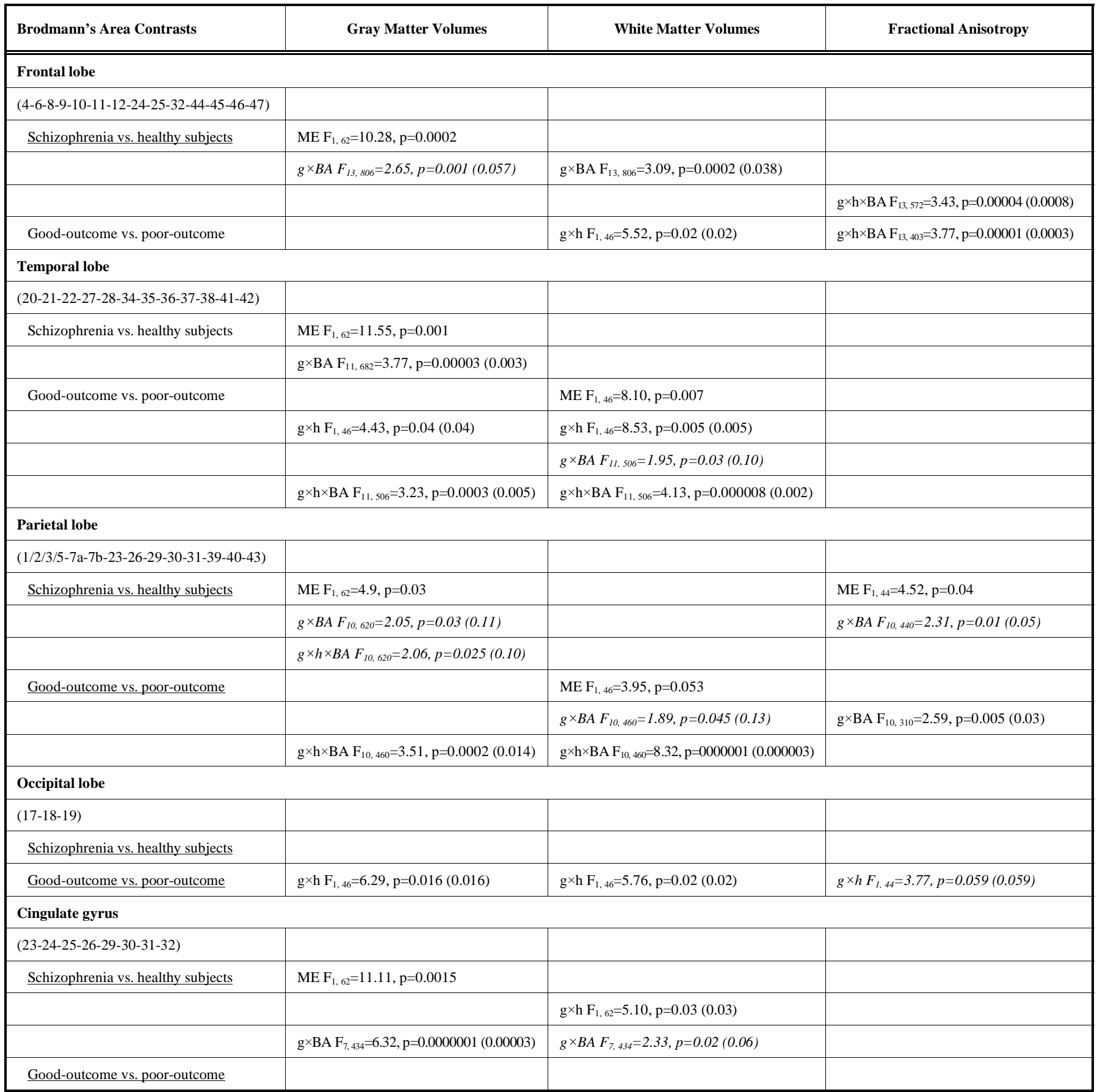

Abbreviations: ME - main effect of diagnosis, $g \times h$ - diagnostic group by hemisphere interaction, $g \times B A$ - diagnostic group by Brodmann's area interaction, $g \times h \times B A-$ diagnostic group by hemisphere by Brodmann's area interaction.

Uncorrected $\mathrm{p}$ values are followed by Huynh-Feldt corrected $\mathrm{p}$ in parentheses. Interactions at trend level of significance $(\mathrm{p}<0.10)$ are in italics. Note that parietal areas $1,2,3$, and 5 were combined in these analyses, hence $1 / 2 / 3 / 5$.

area. Finally, in order to explore the predictive value of illness severity at baseline for longitudinal volume/anisotropy change we examined the Pearson's r product-moment correlations between the baseline minus follow-up difference scores (gray and white matter volumes, white matter fractional anisotropy values) in 40 individual Brodmann's areas and the PANSS subscale scores (positive, negative, general) at the time of the baseline scan. We hypothesized that among all patients with schizophrenia those with more severe psychopathology at presentation will display more pronounced tissue loss in the period to follow-up.

\section{RESULTS}

\section{Schizophrenia Patients vs. Healthy Comparison Subjects Baseline Assessment of Regional White Matter Anisotropy}

At baseline, white matter fractional anisotropy was lower in schizophrenia patients than in healthy subjects in the 
frontal areas 9, 11, 12, 32 in the left hemisphere and 9, 25, $44,45,46$ in the right hemisphere, as well as in all parietal areas except 26, 40, and 43 (see Table 2 for significant ANCOVA interactions at baseline). Follow-up t tests for individual Brodmann's areas confirmed lower anisotropy values in schizophrenia patients in left areas 7a, 21, 23, 39, 46 and right areas 7a, 23, 27, 31, 44.

\section{Longitudinal Assessment of Regional White Matter Anisotropy}

Healthy subjects started with higher fractional anisotropy values but displayed a greater decline over time than patients with schizophrenia in the posterior frontal areas $4,6,8$ (especially in the right hemisphere), 10 and 11 in both hemi- spheres, left area 32 and right areas 44, 45, and 47, as well as in the whole temporal lobe (significant group $\times$ time interaction for the temporal lobe; see Table $\mathbf{3}$ for significant ANCOVA interactions). Follow-up t-tests for baseline minus follow-up anisotropy differences in individual Brodmann's areas confirmed this pattern for right orbitofrontal area 11. The only Brodmann's areas where patients with schizophrenia exhibited a greater decline in anisotropy than healthy subjects in the frontal lobe ANCOVA were left anterior cingulate area 24 and orbitofrontal area 12 in both hemispheres. Entering 11 Brodmann's areas from each of the frontal, temporal, and parietal lobes in a 5-way ANCOVA yielded a highly significant group $\times$ time interaction $(\mathrm{p}=0.0064)$, confirming an overall pattern of steeper decline in fractional

Table 3. Significant ANCOVA Interactions for Between-Group Differences in Longitudinal Changes of White Matter Fractional Anisotropy

\begin{tabular}{|c|c|c|}
\hline Brodmann's Area Contrasts & Fractional Anisotropy ${ }^{a}$ & $\begin{array}{c}\text { Fractional Anisotropy } \\
\text { Controlled for Illness Duration }\end{array}$ \\
\hline \multicolumn{3}{|l|}{ Frontal lobe } \\
\hline$\underline{\text { Schizophrenia vs. healthy subjects }}$ & $\mathrm{g} \times \mathrm{t} \times \mathrm{h} \times \mathrm{BA} \mathrm{F}_{13,559}=2.92, \mathrm{p}=0.0004(0.002)$ & \\
\hline Good-outcome vs. poor-outcome & $\mathrm{g} \times \mathrm{t} \times \mathrm{BA} \mathrm{F}_{13,390}=2.16, \mathrm{p}=0.01(0.03)$ & $\mathrm{g} \times \mathrm{t} \times \mathrm{BA} \mathrm{F}_{13,338}=2.17, \mathrm{p}=0.01(0.029)$ \\
\hline$(20-21-22-27-28-34-35-36-37-38-41-42)$ & $\mathrm{g} \times \mathrm{t} \mathrm{F}_{1,43}=4.68, \mathrm{p}=0.036(0.036)$ & \\
\hline \multicolumn{3}{|l|}{$\underline{\text { Schizophrenia vs. healthy subjects }}$} \\
\hline \multicolumn{3}{|l|}{ Good-outcome vs. poor-outcome } \\
\hline \multicolumn{3}{|l|}{ Parietal lobe } \\
\hline Good-outcome vs. poor-outcome & $\mathrm{g} \times \mathrm{t} \times \mathrm{h} \times \mathrm{BA} \mathrm{F}_{10,300}=2.58, \mathrm{p}=0.005(0.019)$ & $\mathrm{g} \times \mathrm{t} \times \mathrm{h} \times \mathrm{BA} \mathrm{F}_{10,260}=2.58, \mathrm{p}=0.01(0.036)$ \\
\hline \multicolumn{3}{|l|}{ Occipital lobe } \\
\hline \multicolumn{3}{|l|}{$(17-18-19)$} \\
\hline$\underline{\text { Schizophrenia vs. healthy subjects }}$ & $\mathrm{g} \times \mathrm{tF}_{1,30}=4.85, \mathrm{p}=0.036(0.036)$ & \\
\hline Good-outcome vs. poor-outcome & $\mathrm{g} \times \mathrm{t} \times \mathrm{BA} \mathrm{F}_{2,60}=9.21, \mathrm{p}=0.0003(0.0003)$ & $\mathrm{g} \times \mathrm{t} \times \mathrm{BA} \mathrm{F}_{2,52}=7.49, \mathrm{p}=0.001(0.001)$ \\
\hline \multicolumn{3}{|l|}{ Cingulate gyrus } \\
\hline \multicolumn{3}{|l|}{$(23-24-25-26-29-30-31-32)$} \\
\hline \multicolumn{3}{|l|}{$\underline{\text { Schizophrenia vs. healthy subjects }}$} \\
\hline Good-outcome vs. poor-outcome & $\mathrm{g} \times \mathrm{t} \mathrm{F}_{1,30}=6.65, \mathrm{p}=0.015(0.015)$ & $\mathrm{g} \times \mathrm{t} \times \mathrm{h} \times \mathrm{r} \times \mathrm{BA} \mathrm{F}_{20,520}=1.90, \mathrm{p}=0.01(0.04)$ \\
\hline
\end{tabular}

Abbreviations: $\mathrm{g} \times \mathrm{t}-$ diagnostic group by scan time interaction, $\mathrm{g} \times \mathrm{t} \times \mathrm{BA}-$ diagnostic group by time by Brodmann's area interaction, $\mathrm{g} \times \mathrm{t} \times \mathrm{h} \times \mathrm{BA}-$ diagnostic group by time by hemisphere by Brodmann's area interaction, $\mathrm{g} \times \mathbf{t} \times \mathbf{r} \times \mathrm{BA}-$ diagnostic group by time by region by Brodmann's area interaction, $\mathrm{g} \times \mathrm{t} \times \mathrm{h} \times \mathbf{r} \times \mathrm{BA}-\mathrm{diagnostic}$ group by time by hemisphere by region by Brodmann's area interaction.

Uncorrected $\mathrm{p}$ values are followed by Huynh-Feldt corrected $\mathrm{p}$ in parentheses. Interactions at trend level of significance $(\mathrm{p}<0.10)$ are in italics. Note that parietal areas $1,2,3$, and 5 were combined in these analyses, hence $1 / 2 / 3 / 5$.

${ }^{a}$ ANCOVA with subjects' age and interscan interval as covariates

' ANCOVA with subjects' age, interscan interval and illness duration as covariates. 

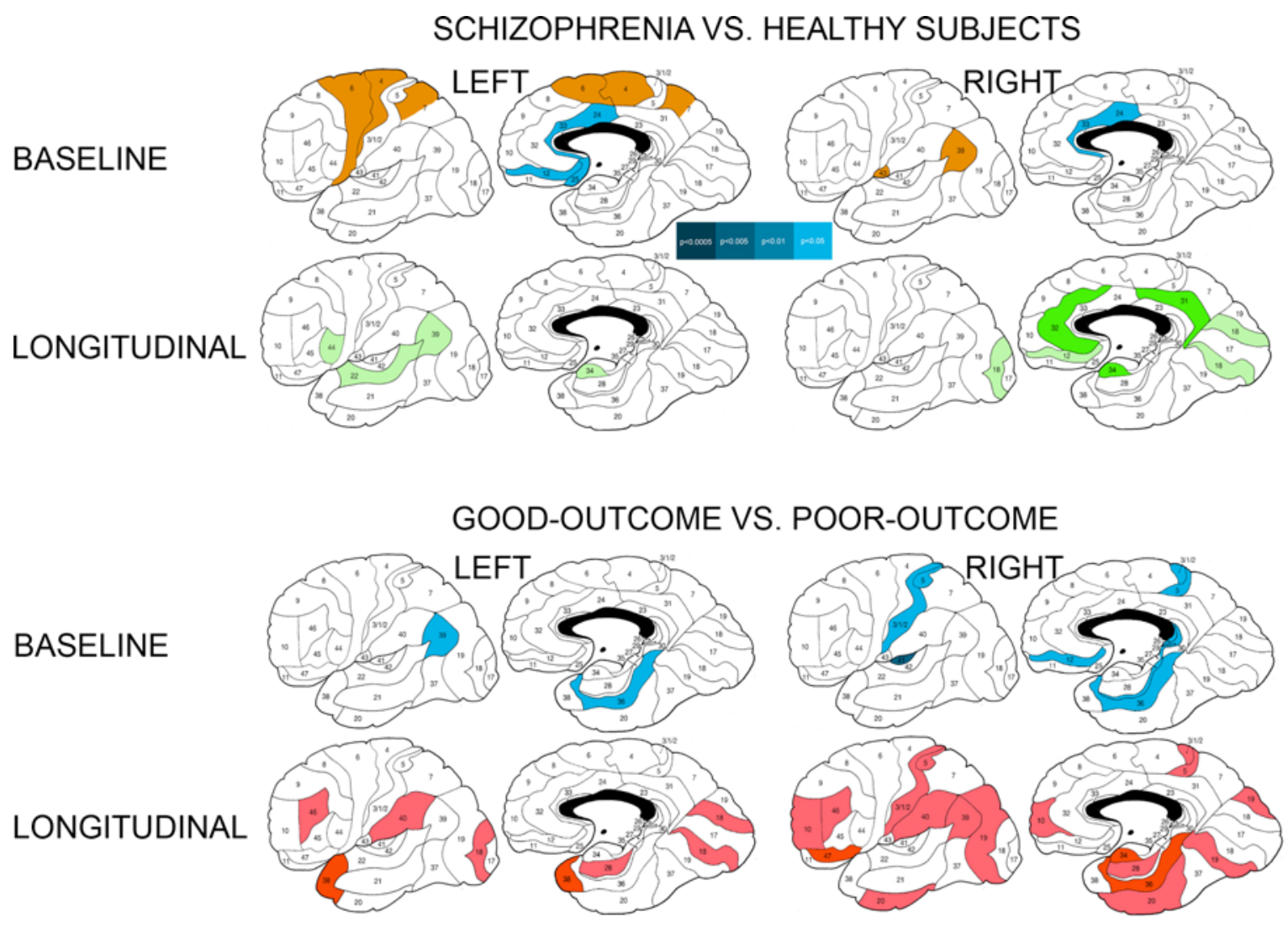

Fig. (1). Differences in baseline relative white matter volumes and their longitudinal changes between patients with schizophrenia and healthy subjects and between schizophrenia patients with good and poor outcomes ${ }^{a}$. ${ }^{a}$ Significant between-group differences as assessed with Student's t test for each Brodmann's area (two-tailed p-values are color-coded in the bar). Baseline volumes: Blue colors denote areas with smaller relative white matter volumes in patients with schizophrenia than in healthy subjects and in poor-outcome patients in comparison to patients with good outcome at two-tailed $\mathrm{p}<0.05$ (indigo) and $\mathrm{p}<0.1$ (trend, light-blue). Brown color indicates areas with larger white matter volumes in patients with schizophrenia than in healthy subjects. Longitudinal changes (relative volumes at baseline scan minus relative volumes at follow-up scan): Green colors indicate areas with greater volume increase in healthy subjects than in schizophrenia patients at two-tailed $\mathrm{p}<0.05$ (dark-green) and $\mathrm{p}<0.1$ (trend, light-green). Red colors indicate areas with greater volume increase in poor-outcome patients than in patients with good outcome at $\mathrm{p}<0.05$ (burgundy hue) and $\mathrm{p}<0.1$ (trend, scarlet hue).

anisotropy values in healthy subjects as compared to patients with schizophrenia. Separate analyses of the cingulate arch, parietal, and occipital lobes produced no significant interactions.

\section{Baseline Assessment of Regional White Matter Volumes}

Schizophrenia patients showed a pattern of larger relative white matter volumes than healthy subjects in the posterior frontal areas 4, 6, and to a lesser degree 8 (Table 2). White matter volumes were smaller in patients with schizophrenia than in healthy subjects in the anterior cingulate area 24 (especially in the right hemisphere) and to a lesser degree in the orbitofrontal area 11. Follow-up t tests for individual Brodmann's areas confirmed larger white matter volumes in patients with schizophrenia in a contiguous region underlying left posterior frontal/postcentral areas 4, 6, $7 \mathrm{a}$ and smaller volumes in the anterior cingulate and orbital frontal areas (Fig. 1).

\section{Longitudinal Assessment of Regional White Matter Volumes}

There were trend-level interactions for absolute volumes in the cingulate gyrus and parietal lobe, and no significant
ANCOVA interactions in any of the relative volume analyses (Table 4). Student's t-tests for baseline minus follow-up volume differences in individual Brodmann's areas yielded more widespread differences for the absolute than relative tissue volumes and indicated that healthy subjects expanded white matter volumes significantly more than patients with schizophrenia in isolated Brodmann's areas of each lobe in both hemispheres (Fig. 1).

\section{Baseline Assessment of Regional Gray Matter Volumes}

At baseline, schizophrenia patients had smaller relative gray matter volumes than healthy subjects in the whole frontal, temporal, and parietal lobes (significant main effects of diagnosis, Table 2). As evidenced by higher-order interactions, this pattern was observed in every Brodmann's area in the frontal lobe, all areas in the temporal lobe with the exclusion of areas 34 and 35 (especially marked in areas 21, 22, and 20), all areas in the parietal lobe (especially marked in areas 1-2-3-5, 31, 39, 40, and 43), and all cingulate areas with the exclusion of areas 25 and 26. Follow-up t tests for individual Brodmann's areas strongly confirmed this pattern as illustrated in Fig. (2). 
Table 4. Significant ANCOVA Interactions for Between-Group Differences in Longitudinal Changes of Absolute and Relative White Matter Volumes

\begin{tabular}{|c|c|c|c|c|}
\hline Brodmann's Area Contrasts & Absolute Volumes $^{\text {a }}$ & $\begin{array}{l}\text { Absolute Volumes Controlled } \\
\text { for Illness Duration }\end{array}$ & Relative Volumes $^{\text {a }}$ & $\begin{array}{l}\text { Relative Volumes Controlled } \\
\text { for Illness Duration }\end{array}$ \\
\hline \multicolumn{5}{|l|}{ Frontal lobe } \\
\hline \multicolumn{5}{|c|}{$(4-6-8-9-10-11-12-24-25-32-44-45-46-47)$} \\
\hline \multicolumn{5}{|l|}{ Schizophrenia vs. healthy subjects } \\
\hline \multirow[t]{2}{*}{ Good-outcome vs. poor-outcome } & & $\mathrm{g} \times \mathrm{t} \mathrm{F}_{1,38}=5.24, \mathrm{p}=0.028(0.028)$ & $\mathrm{g} \times \mathrm{t} \mathrm{F}_{1,45}=4.07, \mathrm{p}=0.0497(0.0497)$ & $\mathrm{g} \times \mathrm{t} \mathrm{F}_{1,38}=4.81, \mathrm{p}=0.035(0.035)$ \\
\hline & $\begin{array}{l}\mathrm{g} \times \mathrm{t} \times \mathrm{BA} \mathrm{F}_{13,585}=2.46, \mathrm{p}=0.003 \\
(0.07)\end{array}$ & $\begin{array}{l}\mathrm{g} \times \mathrm{t} \times \mathrm{BA} \mathrm{F}_{13,494}=4.08 \\
\mathrm{p}=0.000002(0.01)\end{array}$ & $\begin{array}{l}\mathrm{g} \times \mathrm{t} \times \mathrm{BA} \mathrm{F} \mathrm{F}_{13,585}=2.73, \mathrm{p}=0.0009 \\
(0.053)\end{array}$ & $\begin{array}{l}\mathrm{g} \times \mathrm{t} \times \mathrm{BA} \mathrm{F}_{13,494}=3.74 \\
\mathrm{p}=0.00001(0.016)\end{array}$ \\
\hline \multicolumn{5}{|l|}{ Temporal lobe } \\
\hline \multicolumn{5}{|c|}{$(20-21-22-27-28-34-35-36-37-38-41-42)$} \\
\hline \multirow[t]{2}{*}{ Schizophrenia vs. healthy subjects } & $\begin{array}{l}g \times t \times B A F_{11,671}=2.02, p=0.02 \\
(0.12)\end{array}$ & & & \\
\hline & & $\begin{array}{l}g \times t \times h \times B A F_{11,671}=1.89, \\
p=0.037(0.13)\end{array}$ & & \\
\hline \multirow[t]{2}{*}{ Good-outcome vs. poor-outcome } & $\mathrm{g} \times \mathrm{t} \mathrm{F}_{1,45}=8.02, \mathrm{p}=0.007(0.007)$ & $\mathrm{g} \times \mathrm{t} \mathrm{F}_{1,38}=7.90, \mathrm{p}=0.008(0.008)$ & $\mathrm{g} \times \mathrm{t} \mathrm{F}_{1,45}=7.53, \mathrm{p}=0.009(0.009)$ & $\mathrm{g} \times \mathrm{t} \mathrm{F}_{1,38}=7.23, \mathrm{p}=0.01(0.01)$ \\
\hline & $\begin{array}{l}\mathrm{g} \times \mathrm{t} \times \mathrm{BA} \mathrm{F}_{11,495}=2.86, \mathrm{p}=0.001 \\
(0.04)\end{array}$ & $\begin{array}{l}g \times t \times B A F_{11,418}=2.70, p=0.002 \\
(0.053)\end{array}$ & $\begin{array}{l}\mathrm{g} \times \mathrm{t} \times \mathrm{BA} \mathrm{F} \mathrm{F}_{11,495}=3.01, \mathrm{p}=0.0007 \\
(0.04)\end{array}$ & $\begin{array}{l}\mathrm{g} \times \mathrm{t} \times \mathrm{BA} \mathrm{F}_{11,418}=2.91, \mathrm{p}=0.001 \\
(0.049)\end{array}$ \\
\hline \multicolumn{5}{|l|}{ Parietal lobe } \\
\hline \multicolumn{5}{|c|}{$(1 / 2 / 3 / 5-7 a-7 b-23-26-29-30-31-39-40-43)$} \\
\hline Schizophrenia vs. healthy subjects & $\begin{array}{l}g \times t \times h \times B A F_{10,610}=2.09 \\
p=0.02(0.09)\end{array}$ & & & \\
\hline \multirow[t]{3}{*}{ Good-outcome vs. poor-outcome } & $\mathrm{g} \times \mathrm{t} \mathrm{F}_{1,45}=4.11, \mathrm{p}=0.048(0.048)$ & $\mathrm{g} \times \mathrm{t} \mathrm{F}_{1,38}=4.63, \mathrm{p}=0.038(0.038)$ & & \\
\hline & $\begin{array}{l}g \times t \times B A F_{10,450}=2.15, p=0.02 \\
(0.10)\end{array}$ & $\begin{array}{l}g \times t \times h F_{1,38}=4.07, p=0.051 \\
(0.051)\end{array}$ & & \\
\hline & $\begin{array}{l}\mathrm{g} \times \mathrm{t} \times \mathrm{h} \times \mathrm{BA} \mathrm{F}_{10,450}=2.82 \\
\mathrm{p}=0.002(0.02)\end{array}$ & $\begin{array}{l}\mathrm{g} \times \mathbf{t} \times \mathbf{h} \times \mathrm{BA} \mathrm{F}_{10,380}=2.68 \\
\mathrm{p}=0.0036(0.025)\end{array}$ & & \\
\hline \multicolumn{5}{|l|}{ Occipital lobe } \\
\hline \multicolumn{5}{|l|}{$(17-18-19)$} \\
\hline \multicolumn{5}{|l|}{ Schizophrenia vs. healthy subjects } \\
\hline Good-outcome vs. poor-outcome & $\mathrm{g} \times \mathrm{t} \mathrm{F}_{1,45}=4.16, \mathrm{p}=0.047(0.047)$ & $\mathrm{g} \times \mathrm{t} \mathrm{F}_{1,38}=4.40, \mathrm{p}=0.04(0.04)$ & $\mathrm{g} \times \mathrm{t} \mathrm{F}_{1,45}=4.9, \mathrm{p}=0.032(0.032)$ & $\mathrm{g} \times \mathrm{t} \mathrm{F}_{1,38}=4.70, \mathrm{p}=0.037(0.037)$ \\
\hline \multicolumn{5}{|l|}{ Cingulate gyrus } \\
\hline \multicolumn{5}{|l|}{$(23-24-25-26-29-30-31-32)$} \\
\hline Schizophrenia vs. healthy subjects & $g \times t F_{l, 61}=3.79, p=0.056(0.056)$ & & & \\
\hline \multicolumn{5}{|l|}{ Good-outcome vs. poor-outcome } \\
\hline \multicolumn{5}{|c|}{ Frontal (4-6-8-9-10-11-12-44-45-46-47) vs. } \\
\hline \multicolumn{5}{|c|}{ temporal (20-21-22-27-28-34-35-36-38-41-42) vs. } \\
\hline \multicolumn{5}{|c|}{ parietal (1/2/3/5-7a-7b-23-26-29-30-31-39-40-43) } \\
\hline \multicolumn{5}{|l|}{ Schizophrenia vs. healthy subjects } \\
\hline \multirow[t]{2}{*}{ Good-outcome vs. poor-outcome } & $\mathrm{g} \times \mathrm{t} \mathrm{F}_{1,45}=6.53, \mathrm{p}=0.014(0.014)$ & $\mathrm{g} \times \mathrm{tF}_{1,38}=6.95, \mathrm{p}=0.01(0.01)$ & $\mathrm{g} \times \mathrm{t} \mathrm{F}_{1,45}=6.42, \mathrm{p}=0.015(0.015)$ & $\mathrm{g} \times \mathrm{t} \mathrm{F}_{1,38}=6.59, \mathrm{p}=0.014(0.014)$ \\
\hline & $\begin{array}{l}\mathrm{g} \times \mathrm{t} \times \mathrm{r} \times \mathrm{BA} \mathrm{F}_{20,760}=21.73 \\
\mathrm{p}=0.024(0.10)\end{array}$ & $\begin{array}{l}\mathrm{g} \times \mathrm{t} \times \mathbf{r} \times \mathrm{BA} \mathrm{F}_{20,900}=2.08 \\
\mathrm{p}=0.004(0.04)\end{array}$ & $\begin{array}{l}\mathrm{g} \times \mathrm{t} \times \mathbf{r} \times \mathrm{BA} \mathrm{F}_{20,760}=2.86 \\
\mathrm{p}=0.0003(0.005)\end{array}$ & \\
\hline
\end{tabular}

Abbreviations: $\mathrm{g} \times \mathrm{t}-$ diagnostic group by scan time interaction, $\mathrm{g} \times \mathrm{t} \times \mathrm{BA}-$ diagnostic group by time by Brodmann's area interaction, $\mathrm{g} \times \mathrm{t} \times \mathrm{h} \times \mathrm{BA}-$ diagnostic group by time by hemisphere by Brodmann's area interaction, $\mathrm{g} \times \mathrm{t} \times \mathbf{r} \times \mathrm{BA}-$ diagnostic group by time by region by Brodmann's area interaction, $\mathrm{g} \times \mathrm{t} \times \mathrm{h} \times \mathbf{r} \times \mathrm{BA}-\mathrm{diagnostic}$ group by time by hemisphere by region by Brodmann's area interaction.

Uncorrected $\mathrm{p}$ values are followed by Huynh-Feldt corrected $\mathrm{p}$ in parentheses. Interactions at trend level of significance $(\mathrm{p}<0.10)$ are in italics. Note that parietal areas $1,2,3$, and 5 were combined in these analyses, hence $1 / 2 / 3 / 5$.

'ANCOVA with subjects' age and interscan interval as covariates (full sample)

'ANCOVA with subjects' age, interscan interval and illness duration as covariates (subsample of schizophrenia patients) 


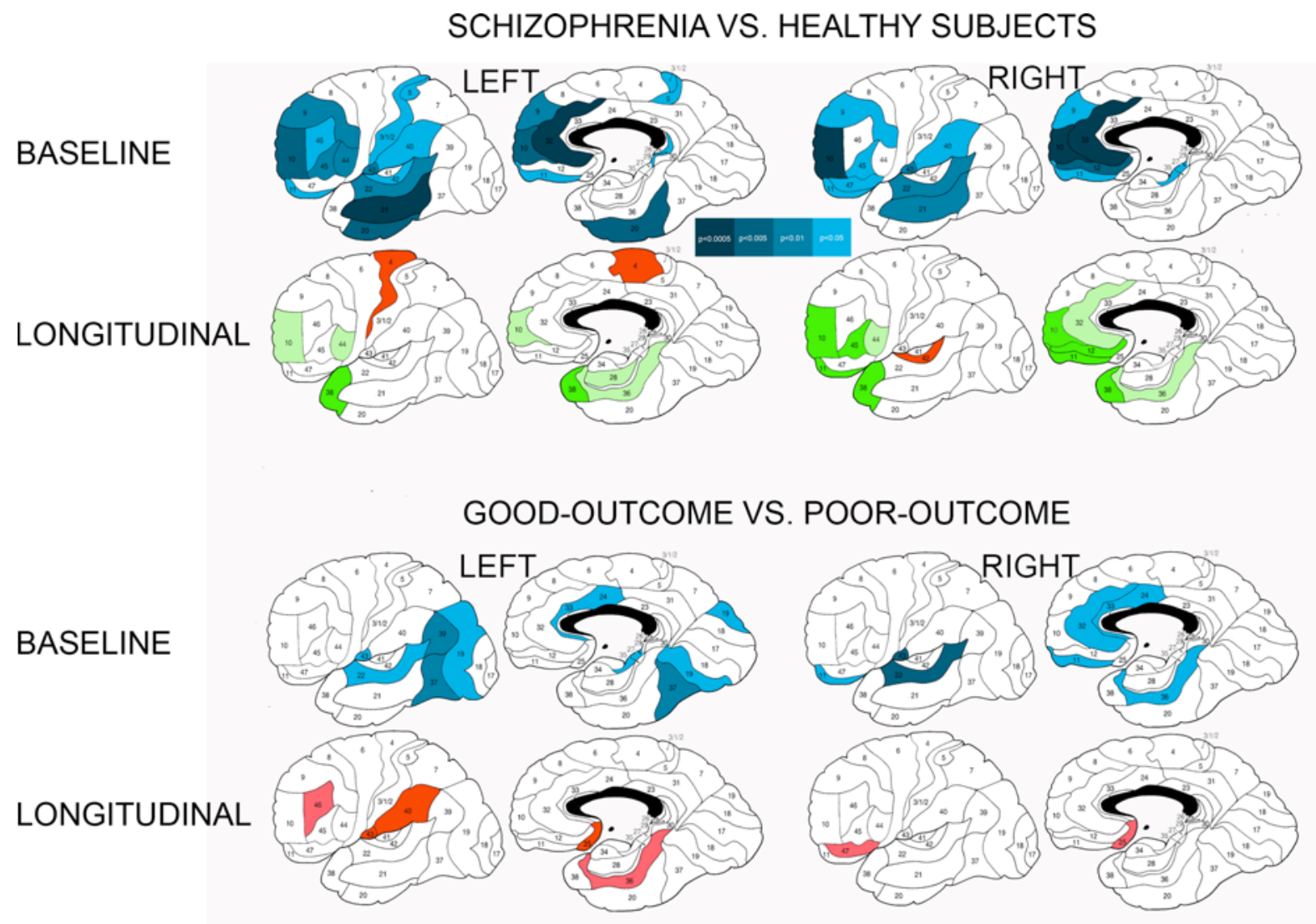

Fig. (2). Differences in baseline relative gray matter volumes and their longitudinal changes between patients with schizophrenia and healthy subjects and between schizophrenia patients with good and poor outcomes ${ }^{\mathrm{a}}{ }^{\text {a }}$ Significant between-group differences as assessed with Student's t test for each Brodmann's area (two-tailed p-values are color-coded in the bar). Baseline volumes: Blue colors denote areas with smaller relative gray matter volumes in patients with schizophrenia than in healthy subjects and in poor-outcome patients in comparison to patients with good outcome. Longitudinal changes (relative volumes at baseline scan minus relative volumes at follow-up scan): Green colors indicate areas with greater volume decline in healthy subjects than in schizophrenia patients at two-tailed $\mathrm{p}<0.05$ (dark-green) and $\mathrm{p}<0.1$ (trend, light-green). Red colors indicate areas with greater volume decline in schizophrenia patients than healthy subjects or in pooroutcome patients than in patients with good outcome at $\mathrm{p}<0.05$ (burgundy hue) and $\mathrm{p}<0.1$ (trend, scarlet hue).

\section{Longitudinal Assessment of Regional Gray Matter Volumes}

Absolute and relative volume analyses produced very similar results (Table 5). ANCOVAs for the medial and lateral temporal regions indicated that healthy subjects entered the study with larger gray matter volumes and had a greater decline over time than patients with schizophrenia in both medial and lateral areas 22, 28 in the left hemisphere and 21, $22,28,36$ in the right hemisphere; only in area 42 (primary auditory cortex) and especially in the right hemisphere did patients with schizophrenia show a steeper volume decline than healthy comparison subjects. In the frontal lobe, there was a trend towards a similar pattern of greater volume decline in healthy subjects in most of the areas (and especially 8,9 , and 10), except the posterior frontal areas 4 and 6 , where patients with schizophrenia evidenced a greater decline in volumes than healthy subjects.

When 11 Brodmann's areas from each of the frontal, temporal, and parietal lobes were entered into a 5-way ANCOVA, there was a trend towards a pattern of a steeper gray matter volume decline over the period to follow-up in healthy subjects than patients with schizophrenia in the frontal areas 9 and 10, to a lesser degree 32 and 44 and in the temporal areas $20,21,22,28,36$, and 38 . Only in the temporal areas 37 and 42, as well as frontal areas 4 and 6 did patients with schizophrenia display a trend towards greater longitudinal decline in gray matter volume than healthy comparison subjects. There were no significant interactions in the analyses of the cingulate arch, parietal or occipital lobes. Follow-up t-tests for baseline minus follow-up volume differences in individual Brodmann's areas confirmed this pattern for selected frontotemporal areas as illustrated in Fig. (2).

There were no significant differences between healthy subjects and patients with schizophrenia in the longitudinal change in whole brain, total gray matter or total white matter volumes.

\section{Patients with Good Outcomes vs. Patients with Poor Outcomes \\ Baseline Assessment of Regional White Matter Anisotropy}

At baseline, patients with poor outcome showed a pattern of lower fractional anisotropy than patients with good outcome in the left frontal areas 10, 44, 45, 46 and in every 
Table 5. Significant ANCOVA Interactions for Between-Group Differences in Longitudinal Changes of Absolute and Relative Gray Matter Volumes

\begin{tabular}{|c|c|c|c|c|}
\hline Brodmann's Area Contrasts & Absolute Volumes ${ }^{\mathrm{a}}$ & $\begin{array}{l}\text { Absolute Volumes Controlled } \\
\text { for Illness Duration }\end{array}$ & Relative Volumes $^{\text {a }}$ & $\begin{array}{l}\text { Relative Volumes Controlled } \\
\text { for Illness Duration }\end{array}$ \\
\hline \multicolumn{5}{|l|}{ Frontal lobe } \\
\hline \multicolumn{5}{|c|}{$(4-6-8-9-10-11-12-24-25-32-44-45-46-47)$} \\
\hline$\underline{\text { Schizophrenia vs. healthy subjects }}$ & $\begin{array}{l}g \times t \times B A F_{13,793}=2.26, p=0.006 \\
(0.09)\end{array}$ & & $\begin{array}{l}g \times t \times B A F_{13,793}=2.17 \\
p=0.009(0.10)\end{array}$ & \\
\hline \multirow[t]{2}{*}{ Good-outcome vs. poor-outcome } & & $\mathrm{g} \times \mathrm{t} \mathrm{F}_{1,38}=4.56, \mathrm{p}=0.04(0.04)$ & & \\
\hline & & $\begin{array}{l}\mathrm{g} \times \mathrm{t} \times \mathrm{BA} \mathrm{F} \mathrm{F}_{13,494}=3.40, \mathrm{p}=0.00005 \\
(0.03)\end{array}$ & & $\begin{array}{l}g \times t \times B A F_{13,494}=2.82, p=0.0007 \\
(0.052)\end{array}$ \\
\hline
\end{tabular}

Temporal lobe

$(20-21-22-27-28-34-35-36-37-38-41-42)$

Schizophrenia vs. healthy subjects

$\mid$

$g \times t \times B A F_{11,671}=2.18$, $p=0.014(0.088)$

Good-outcome vs. poor-outcome

Lateral (20-21-22-41-42) vs. medial

(27-28-34-35-36) temporal regions

Schizophrenia vs. healthy subjects

\begin{tabular}{|c|}
\hline $\begin{array}{l}g \times t \times r \times B A F_{4,244}=2.95, p=0.02 \\
(0.06)\end{array}$ \\
\hline $\begin{array}{l}\mathrm{g} \times \mathrm{t} \times \mathrm{h} \times \mathrm{r} \times \mathrm{BA} \mathrm{F}_{4,244}=2.97, \mathrm{p}=0.02 \\
(0.04)\end{array}$ \\
\hline
\end{tabular}

$\mathrm{g} \times \mathbf{t} \times \mathbf{r} \times \mathrm{BA} \mathrm{F}_{4,244}=3.85$, $\mathrm{p}=0.005(0.02)$

Good-outcome vs. poor-outcome

\section{Parietal lobe}

(1/2/3/5-7a-7b-23-26-29-30-31-39-40-43)

Schizophrenia vs. healthy subjects

\begin{tabular}{l|l} 
Good-outcome vs. poor-outcome & $\mathrm{g} \times \mathrm{t} \mathrm{F}_{1,38}=4.44, \mathrm{p}=0.04(0.04$
\end{tabular}

$g \times t \times B A F_{10,450}=2.28, p=0.01$ $(0.09)$

$g \times t \times h \times B A F_{10,450}=2.60$, $p=0.0045(0.057)$

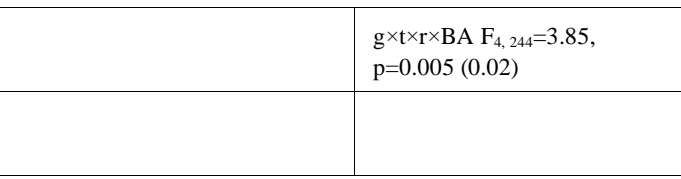

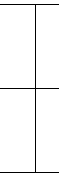

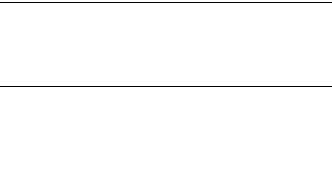

\begin{tabular}{|l|l} 
& $(0.09)$ \\
\hline$g \times t \times h \times B A F_{10,450}=2.60$, \\
$p=0.0045(0.057)$
\end{tabular}

\begin{tabular}{|l|}
\hline $\begin{array}{l}g \times t \times B A F_{10,380}=2.67, p=0.004 \\
(0.054)\end{array}$ \\
$\begin{array}{l}\mathrm{g} \times \mathrm{t} \times \mathrm{h} \times \mathrm{BA} \mathrm{F}_{10,380}=2.60 \\
\mathrm{p}=0.000004(0.004)\end{array}$ \\
\hline
\end{tabular}

\begin{tabular}{|l|l} 
& \\
\hline $\begin{array}{l}g \times t \times B A F_{10,450}=2.35, \\
p=0.01(0.08)\end{array}$ & $\begin{array}{l}g \times t \times B A F_{10,380}=2.26, p=0.01 \\
(0.09)\end{array}$ \\
$\begin{array}{l}\mathrm{g} \times \mathrm{t} \times \mathrm{h} \times \mathrm{BA} \mathrm{F} \mathrm{F}_{10,450}=2.87, \\
\mathrm{p}=0.0017(0.036)\end{array}$ & $\begin{array}{l}\mathrm{g} \times \mathrm{t} \times \mathrm{h} \times \mathrm{BA} \mathrm{F} \mathrm{F}_{10,380}=4.51, \\
\mathrm{p}=0.000005(0.003)\end{array}$
\end{tabular}

Occipital lobe

$(17-18-19)$

Schizophrenia vs. healthy subjects

Good-outcome vs. poor-outcome

$\mathrm{g} \times \mathrm{t} \times \mathrm{h} \times \mathrm{BA} \mathrm{F}{ }_{2,76}=4.12, \mathrm{p}=0.02$ (0.036)

Cingulate gyrus

(23-24-25-26-29-30-31-32)

Schizophrenia vs. healthy subjects

Good-outcome vs. poor-outcome

$\mid$

$\left.\mathrm{g} \times \mathrm{t}_{1,38}=6.59, \mathrm{p}=0.0140 .014\right)$
$\mathrm{g} \times \mathrm{t} \times \mathrm{BA} \mathrm{F}_{7,266}=3.14, \mathrm{p}=0.003$
$(0.028)$

$\mathrm{g} \times \mathrm{t} \mathrm{F}_{1,38}=4.12, \mathrm{p}=0.0496$ (0.0496)

$g \times t \times B A F_{7,266}=2.34, p=0.025$ (0.075)

Frontal (4-6-8-9-10-11-12-44-45-46-47) vs

temporal (20-21-22-27-28-34-35-36-38-41-42) vs.

parietal (1/2/3/5-7a-7b-23-26-29-30-31-39-40-43) 
Table 5 cont....

\begin{tabular}{|c|c|c|c|c|}
\hline Brodmann's Area Contrasts & Absolute Volumes $^{\mathrm{a}}$ & $\begin{array}{l}\text { Absolute Volumes Controlled } \\
\text { for Illness Duration }\end{array}$ & Relative Volumes $^{\mathrm{a}}$ & $\begin{array}{l}\text { Relative Volumes Controlled } \\
\text { for Illness Duration }\end{array}$ \\
\hline \multirow[t]{2}{*}{$\underline{\text { Schizophrenia vs. healthy subjects }}$} & $\begin{array}{l}g \times t \times r \times B A \quad F_{20,1220}=1.85, p=0.01 \\
(0.08)\end{array}$ & & $\begin{array}{l}g \times t \times r \times B A F_{20,1220}=1.92, \\
p=0.009(0.06)\end{array}$ & \\
\hline & & $\begin{array}{l}g \times t \times h \times r \times B A F_{20,1220}=2.42, \\
p=0.0006(0.054)\end{array}$ & $\begin{array}{l}g \times t \times h \times r \times B A F_{20,1220}=2.42, \\
p=0.0005(0.052)\end{array}$ & \\
\hline \multirow[t]{2}{*}{ Good-outcome vs. poor-outcome } & $\mathrm{g} \times \mathrm{t} \mathrm{F}_{1,45}=4.06, \mathrm{p}<0.05(<0.05)$ & $\mathrm{g} \times \mathrm{t} \mathrm{F}_{1,38}=4.52, \mathrm{p}=0.04(0.04)$ & & $\begin{array}{l}\mathrm{g} \times \mathrm{t} \times \mathrm{r} \times \mathrm{BA} \mathrm{F}_{2,76}=4.31, \mathrm{p}=0.017 \\
(0.017)\end{array}$ \\
\hline & & $\begin{array}{l}g \times t \times r \times B A \quad F_{20,760}=1.90, p=0.01 \\
(0.096)\end{array}$ & & \\
\hline
\end{tabular}

Abbreviations: $\mathrm{g} \times \mathrm{t}$ - diagnostic group by scan time interaction, $\mathrm{g} \times \mathrm{t} \times \mathrm{BA}-$ diagnostic group by time by Brodmann's area interaction, $\mathrm{g} \times \mathrm{t} \times \mathrm{h} \times \mathrm{BA}-\mathrm{diagnostic}$ group by time by hemisphere by Brodmann's area interaction, $\mathrm{g} \times \mathrm{t} \times \mathrm{r} \times \mathrm{BA}-$ diagnostic group by time by region by Brodmann's area interaction, $\mathrm{g} \times \mathrm{t} \times \mathrm{h} \times \mathbf{r} \times \mathrm{BA}-$ diagnostic group by time by hemisphere by region by Brodmann's area interaction

Uncorrected $\mathrm{p}$ values are followed by Huynh-Feldt corrected $\mathrm{p}$ in parentheses. Interactions at trend level of significance $(\mathrm{p}<0.10)$ are in italics. Note that parietal areas $1,2,3$, and 5 were combined in these analyses, hence $1 / 2 / 3 / 5$.

aANCOVA with subjects' age and interscan interval as covariates (full sample of participants)

'ANCOVA with subjects' age, interscan interval and illness duration as covariates (subsample of schizophrenia patients).

parietal area except 1-2-3-5, 7a, and 7b, where anisotropy was higher in the poor-outcome group (Table 2). Follow-up t-tests for individual Brodmann's areas did not produce significant results.

\section{Longitudinal Assessment of Regional White Matter Anisotropy}

Patients with schizophrenia with good outcome started with higher anisotropy values but displayed a steeper decline over time than patients with poor outcome in Brodmann's areas 9, 23, 24 (especially in the left hemisphere), 25, 44, 45, 47 in both hemispheres, right area 31 and left area 43 (see interactions for the frontal, parietal, and cingulate analyses in Table 3 and diagram in Fig. (3). Entering 11 Brodmann's areas from each of the frontal, temporal, and parietal lobes into a 4-way ANCOVA yielded a significant diagnostic group $\times$ time interaction, suggesting an overall pattern of greater decline in fractional anisotropy over time in patients with good outcome everywhere with the exception of the occipital lobes. Controlling for illness duration slightly weakened the results but did not principally change them.

Poor-outcome patients showed a greater increase in fractional anisotropy values over time than patients with good outcome in areas 17, 18, 26, 30 in both hemispheres, 7a and 29 in the left hemisphere, as well as overall in the occipital lobe (significant diagnostic group $\times$ time and higherorder interactions for the occipital lobe, see also significant interactions for the parietal lobe and cingulate arch). Pooroutcome patients showed a greater decline in anisotropy than patients with good outcome in the frontal areas 4, 6, and 12 in both hemispheres, as well as right parietal areas 1-2-3-5, $7 \mathrm{a}, 7 \mathrm{~b}$, and 43 (see significant interactions for the frontal and parietal lobes in Table 3). Analyses of the temporal lobe and follow-up t tests for individual Brodmann's areas yielded no significant results.

\section{Baseline Assessment of Regional White Matter Volumes}

At baseline, patients with poor outcome had smaller relative white matter volumes than patients with good outcome in the whole temporal and occipital lobes (significant main effects of diagnosis), more pronounced in the right hemisphere, and at a trend level in the whole parietal lobe (Table 2). Based on the higher-order interactions, this was evident in every temporal area except right area 42 (especially marked in areas 20,21, 22, 36, and left area 42) and in the parietal areas 39, 40, and left area 1-2-3-5. Follow-up t tests for individual Brodmann's areas confirmed smaller white matter volumes in the poor-outcome group in a set of temporal, restrosplenial cingulate and isolated frontoparietal areas (Fig. 1).

\section{Longitudinal Assessment of Regional White Matter Volumes}

Absolute and relative volume analyses yielded similar results (Table 4). As the overall pattern of longitudinal
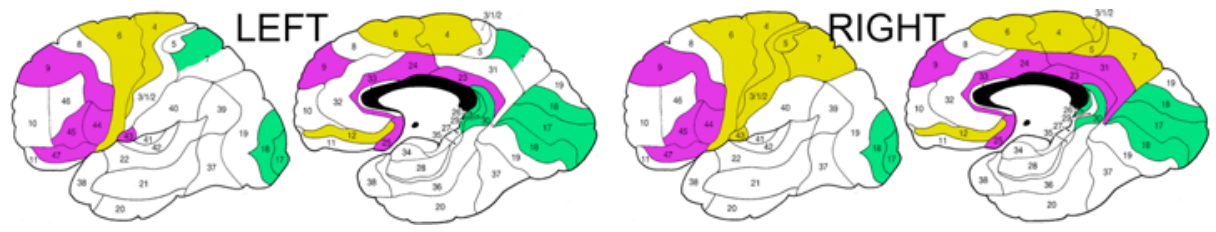

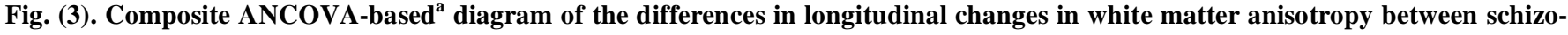
phrenia patients with good and poor outcomes. ${ }^{a}$ Significant diagnostic group $\times$ time $\times$ Brodmann's area interactions in all ANCOVAs are illustrated based on the decomposition of the mean effects for individual Brodmann's areas. Lilac color indicates areas with greater anisotropy decline in patients with good outcome than in patients with poor outcome. Khaki color indicates areas with greater anisotropy decline in patients with poor outcome than in patients with good outcome. Green color indicates areas with greater anisotropy increase in patients with poor outcome than in patients with good outcome. Areas with between-group ANCOVA differences in relative anisotropy of less than 0.2 points were left blank. 
changes in white matter volumes, poor-outcome schizophrenia patients started with smaller volumes but expanded over time significantly more than patients with good outcome. This was evident in the whole frontal lobe (significant diagnostic group $\times$ time interaction) with localized differences in the frontal areas $4,6,8,9,10$, and, to a lesser extent, 46 (significant diagnostic group $\times$ time $\times$ Brodmann's area interaction); in the whole temporal lobe (highly significant diagnostic group $\times$ time interaction), specifically in areas $20,21,22$, $28,36,37$, and 38 (significant diagnostic group $\times$ time $\times$ Brodmann's area interaction); and in the whole occipital lobe (significant diagnostic group $\times$ time interaction). In addition, absolute but not relative volume analyses evidenced the same pattern in the parietal lobe as well (significant diagnostic group $\times$ time interaction), specifically in the right areas 1-2-3-5, 39, and 40 (significant diagnostic group $\times$ time $\times$ hemisphere $\times$ Brodmann's area interaction). Entering 11 Brodmann's areas from each of the frontal, temporal, and parietal lobes into an ANCOVA yielded a significant diagnostic group $\times$ time interaction, suggestive of an overall pattern of greater white matter volume expansion in the poor-outcome schizophrenia group. Controlling for illness duration strengthened these results for the frontal lobe and slightly weakened the results for the temporal lobe, leaving everything else principally unchanged. ANCOVA for the cingulate arch did not produce significant interactions.

Follow-up t-tests for baseline minus follow-up volume differences in individual Brodmann's areas similarly indicated that patients with poor outcome expanded white matter volumes over time significantly more than those with good outcome in the temporal and orbitofrontal areas and at a trend level throughout the brain (Fig. 1).

\section{Baseline Assessment of Regional Gray Matter Volumes}

At baseline, patients with poor outcome showed a pattern of smaller relative gray matter volumes than patients with good outcome in all temporal areas except areas 34, 35, and right area 42 (especially marked decreases in left areas 21 , 22, 36, and 37) and in almost all parietal areas (especially marked in areas $7 \mathrm{~b}, 31,39,40,43$, and left 1-2-3-5). In the occipital lobe, the difference in gray matter volumes between good-outcome and poor-outcome patients was more pronounced in the right than in the left hemisphere (Table 2). Follow-up t-tests for individual Brodmann's areas confirmed smaller gray matter volumes in poor-outcome patients in the anterior cingulate and posterior cerebral cortex (temporal, parietal, and occipital), more widespread in the left hemisphere (Fig. 2).

\section{Longitudinal Assessment of Regional Gray Matter Volumes}

Schizophrenia patients with poor outcome showed a greater decline in gray matter volumes over time than those with good outcome in the parietal areas 40 and 43 in both hemispheres, combined area 1-2-3-5 in the left hemisphere and area 31 in the right hemisphere, even though the pooroutcome group started with already smaller volumes at initial scan (Table 5). Controlling for duration of illness strengthened the results markedly and especially for the absolute tissue volumes, producing significant diagnostic group $\times$ time and higher order interactions in the frontal, parietal, and occipital lobe analyses, the cingulate gyrus, and an overall contrast analysis of the frontal, temporal, and parietal lobes. These results indicated that patients with poor outcomes had a significantly greater gray matter volume declines throughout the brain with the exception of the temporal lobe. Higher-order interactions implicated into this pattern practically every Brodmann's area in the frontal and parietal lobes, cingulate areas 25, 31, and 32, and the right occipital area 18. Follow-up t-tests for baseline minus follow-up volume differences in individual Brodmann's areas confirmed greater decline in volumes in the poor-outcome group in subgenual cingulate, left parietal and right orbitofrontal areas (Fig. 2).

Comparison of longitudinal changes in total brain volumes in schizophrenia patients with good and poor outcomes using Student's t test pointed to a trend towards a differential decline in whole brain volume that was steeper in the pooroutcome group $(\mathrm{p}=0.087)$. Total gray and white matter volumes did not show differential patterns of longitudinal change between these two patient groups.

\section{Correlations between Longitudinal Changes and PANSS Scores at First Scan}

As the overall pattern of correlations between baseline PANSS subscale scores and longitudinal changes in regional brain volumes and anisotropy, schizophrenia patients with higher baseline PANSS scores showed greater expansion in relative white matter volumes and greater decline in fractional anisotropy values as well as relative gray matter volumes over the follow-up period.

General psychopathology subscale scores inversely correlated with changes in temporal and occipital white matter volumes (left areas 17, 41, and right areas 17, 34), and directly correlated with changes in gray matter volumes in left parietal areas 1-2-3-5 and 40. Positive syndrome subscale scores inversely correlated with longitudinal changes in parietal and occipital white matter volumes (left areas 17, 39, and right area 19), and directly correlated with changes in gray matter volumes in left areas 25 (subgenual cingulate) and 40 (lower parietal). Negative syndrome subscale scores inversely correlated with changes in white matter volumes associated with the right temporal area 34 and directly with fractional anisotropy values in left orbitofrontal areas 11, 12, 47 and right areas 1-2-3-5, 7a, 7b, 43 (parietal), 10, 12 (frontal), and 17 (occipital), as well as with changes in gray matter volumes in left upper parietal area $7 \mathrm{~b}$.

\section{DISCUSSION}

\section{Schizophrenia Patients and Healthy Subjects}

In comparison to healthy subjects and in alliance with a large body of neuroimaging literature, middle-aged patients with chronic schizophrenia entered this study with lower anisotropy over extensive frontal and parietal white matter regions and with larger posterior frontal white matter volumes. As could be expected from the prior research, they also displayed reduced gray matter volumes throughout the frontal, temporal, and parietal lobes. These findings are almost identical to our published data from the full original sample of 145 participants and thus add a strong argument against any potential bias in the selection of the current follow-up cohort [40, 41]. Interestingly, a similar regional 
finding of larger white matter volumes at the frontoparietal junction was also recently presented by Whitford et al. in first-episode schizophrenia patients [36].

In the longitudinal four-year follow-up in this study, healthy subjects exhibited regional reductions in fractional anisotropy and gray matter volumes, as well as expansion of regional white matter volumes over the follow-up period, - a pattern that is in agreement with available neuroimaging literature on normal aging in this age group as reviewed elsewhere $[9,13,23]$. As compared to healthy subjects, patients with schizophrenia displayed a pattern of slower decline in gray matter volumes and white matter anisotropy, as well as slower regional white matter expansion. Therefore, overall changes in gray matter volumes, white matter volumes and white matter anisotropy were in the direction of an effacement of between-group differences, seen at baseline assessment.

We hypothesize that pathological changes in both gray and white matter in patients with schizophrenia occur premorbidly and early in the course of their illness, and that the rate of these changes slows down with age. The differences between healthy and schizophrenia subjects in both gray matter and white matter volume as well as white matter anisotropy, seen at earlier stages of illness, then begin to diminish as if schizophrenia patients were ahead of healthy subjects in the normative process of aging. This underscores the importance of illness duration and age in comparative analyses of disparate neuroimaging data, which may be one of the reasons for the notorious heterogeneity of the structural findings in the literature reported to date.

\section{White Matter Anisotropy}

For white matter fractional anisotropy, overall pattern for the frontal, temporal, and parietal white matter as a whole was that of a greater decline over time in healthy subjects than in patients with schizophrenia. The same pattern was more locally observed in the whole temporal lobe, as well as in several frontal regions, where it was more extensive in the right hemisphere. However, in the left anterior cingulate (underlying area 24) and in the orbitofrontal white matter in both hemispheres patients with schizophrenia showed a greater decline in anisotropy than healthy subjects. This latter finding is consistent with a differential timeframe of illness progression in various regions of the brain, with the possibility of a still active pathological process in the anterior cingulate and orbitofrontal white matter at this stage of the illness course.

\section{White Matter Volumes}

For white matter volumes, we observed a greater expansion over time in healthy subjects than in patients with schizophrenia in the isolated right cingulate and temporal regions. These results contrast with those recently reported by van Haren et al. [35], who found a significantly more pronounced whole-brain white matter volume expansion in patients with schizophrenia than in healthy subjects in a 5year follow-up study. Participants in their study were younger than ours $(32.22 \pm 11.10$ vs. $42.69 \pm 12.29$ years old for patients and $35.28 \pm 12.25$ vs. $41.63 \pm 12.23$ years old for healthy subjects at baseline scan), therefore one may conclude that this pattern of more pronounced white matter expansion in schizophrenia patients slows down and at least regionally begins to revert itself in the next decade of life. Indeed, in their regression by age analysis van Haren et al. [35] found that rate of the white matter expansion in schizophrenia patients reduced with age down to a complete halt by approximately age 51 , whereas white matter expansion progressed linearly in healthy comparison subjects throughout the investigated age range. Moreover, differences in the rate of white matter expansion between patients with schizophrenia and healthy subjects were significant only up to the age of 32 years. Our present study extends the results of van Haren et al. [35] by showing that later in life the differences in the rates of changes in white matter volumes not only become statistically indistinguishable but even begin to revert themselves at least regionally due to more pronounced white matter expansion in healthy subjects than in patients with schizophrenia.

It should be emphasized that the similarity of results for absolute and relative tissue volumes in our study mitigates against the possibility of white matter changes being created by a corresponding change in gray matter in the opposite direction. It should also be noted that in follow-up data each participant is their own control hence an absolute volumetric change in cubic millimeters is directly interpretable. Finally, based on our results white matter anisotropy may indeed be more sensitive a measure of longitudinal white matter changes in schizophrenia than volumetric analyses, as has previously been proposed for normal aging [16-18].

\section{Gray Matter Volumes}

For gray matter volumes, there was a greater decline over time in healthy subjects than in patients with schizophrenia in the lateral and medial temporal cortex, as well as the prefrontal region surrounding the pole (areas 9, 10, 32, and 44). Only in the upper lateral temporal area 42 (primary auditory cortex) and in the motor-premotor cortex did patients with schizophrenia continue to lose gray matter volume at a greater rate. Gur et al. [56] previously reported a similarly less pronounced gray matter volume reduction in the temporal lobe over a 2.5-year follow-up in chronic schizophrenia patients than in healthy comparison subjects. These authors compared rates of gray matter volume changes in firstepisode and chronic schizophrenia patients with normal aging changes in healthy subjects. They found that while the younger, first-episode schizophrenia patients displayed a greater decline in the frontal and temporal volumes than healthy comparison subjects, chronic schizophrenia patients displayed a less pronounced gray matter volume reduction in the temporal lobe and no difference in the frontal lobe as compared to healthy comparison subjects. In a small sample of men with chronic schizophrenia and closer to ours in age (39.4 \pm 6.4 for patients and $40.7 \pm 8.5$ for healthy subjects), Mathalon et al. [5] likewise report a trend towards faster decline in left prefrontal gray matter volume in healthy subjects than in patients with schizophrenia and a trend towards a reversed pattern in right prefrontal gray matter.

Our current results thus appear to confirm the findings of Gur et al. [56] for the temporal lobe and detect analogous pattern in a smaller prefrontal region, similar to the findings of Mathalon et al. [5]. In contrast, van Haren et al. [35] report that the continued gray matter volume loss in their younger longitudinal cohort was more pronounced in patients with schizophrenia than in healthy comparison 
subjects. In their study, the loss of gray matter with age accelerated in healthy subjects (between years 29 and 50) and slowed down in schizophrenia patients (up to age 56), so that the intergroup differences in the rate of the decline in volume in the frontal, temporal, and occipital lobes were only significant up to age 46 , and in the parietal lobe only up to age 40. Our present findings show that with further aging the rate of gray matter loss in patients with schizophrenia eventually becomes even slower than in healthy comparison subjects, at least in some temporal and prefrontal regions, so that the between-group volumetric differences eventually begin to narrow.

\section{Schizophrenia Patients with Good and Poor Outcomes}

As compared to the good-outcome group, schizophrenia patients with poor outcome entered the study with lower white matter anisotropy in the frontal and parietal lobes, as well as reduced white matter and gray matter volumes in the posterior (temporal, parietal, and occipital) regions of the brain. This was consistent with our earlier finding of the posteriorization in the gray and white matter volume deficits with poor outcome in schizophrenia $[39,41]$ and of the more widespread anisotropy reductions in these patients [40]. Over the 4-year follow-up period, patients with poor outcome displayed a pattern of slower decline in white matter anisotropy and faster expansion of white matter volumes in comparison to patients with good outcome. Therefore, similarly to the longitudinal changes in all schizophrenia patients and healthy subjects, changes in white matter volume and anisotropy in the good-outcome and poor-outcome schizophrenia subgroups were in the direction of an effacement of between-group differences, seen at baseline assessment. In contrast to this pattern, patients with poor outcome displayed a greater decline in gray matter volumes throughout the brain than patients with good outcome, indicative of a continued progression of the illness-related pathology in the pooroutcome group. These changes were not associated merely with longer illness duration since effects had increased significance levels when illness duration was included as a covariate.

\section{White Matter Anisotropy}

For white matter fractional anisotropy, the overall pattern for the frontal, parietal and temporal lobes was that of a lesser decline in patients with poor outcome than in those with good outcome (especially notable in the prefrontal and anteroposterior cingulate regions). This implies that the anisotropy deficits, documented in these patients throughout most of the brain [40], are the result of an earlier pathophysiological process that took place before or for a relatively limited period after the symptomatic onset of the disease. Moreover, at least in the third decade after the initial diagnosis the anisotropy differences among patients with different outcomes tend to diminish. Yet, a more pronounced decline in anisotropy in patients with poor outcome was seen in a contiguous region of the precentral/postcentral white matter (khaki areas in Fig. 3), which thus suggests a regionally localized progression of white matter pathology in the poor-outcome group even in the chronic phase of the illness. Further, in the occipital lobe and retrosplenial cingulate (green areas in Fig. 3) fractional anisotropy increased with time in both patient groups but significantly more so in patients with poor outcome. This increase in anisotropy may be the aftermath of an undetected co-territorial decline in white matter volume (we have previously documented an inverse relationship among the regional white matter volumes and anisotropy in this same group of patients [40]). Previous cross-sectional studies reported a positive correlation between age and fractional anisotropy in tractographically placed seed points within specific tracts in both healthy and schizophrenia subjects $[57,58]$. Small Brodmann's areas 26,29 , and 30 in the retrosplenial white matter are likely to incorporate mostly the posterior portion of the cingulum, where anisotropy increases with age and this effect may be accentuated by loss of the surrounding extrafascicular white matter in the poor-outcome patient group. The cause notwithstanding, the disparate anisotropy changes in the occipital and posterior cingulate white matter point to a progressive pathological process in patients with poor outcome in these two regions too.

\section{White Matter Volumes}

For white matter volumes, there was an overall pattern of a greater volume expansion in patients with poor outcome than in the good-outcome group, involving all lobes. In the frontal lobe, this pattern was further localizable to the precentral (areas 4, 6, 8) and polar (areas 9, 10) regions. In this vein, van Haren et al. [35] reported a direct association between the increase in the whole-brain white matter volume and a number of hospitalizations during the period to followup in a chronic schizophrenia patient group.

\section{Gray Matter Volumes}

For gray matter, we found a greater cortical volume loss over time in patients with poor outcome throughout the brain. In a 5-year longitudinal voxel-based and region-ofinterest morphometry study in a younger group of participants, van Haren et al. [31, 35] showed that excessive decreases in the medial frontal polar (areas 9 and 10) and left upper temporal (area 42) gray matter density, as well as volume, were associated with a higher number of hospitalizations, i.e. more severe course of the illness in the Kraepelinian sense (see the outcome classification criteria in the Methods section). Mathalon et al. [5], too, found an association between a more severe negative syndrome (as reflected by higher BPRS scores), as well as longer periods of hospitalization, and a greater decline in the prefrontal and temporal gray matter volume over time in a group of chronic schizophrenia patients. Davis et al. [59] reported a greater ventricular expansion over a 5-year period in chronic Kraepelinian schizophrenia patients in comparison to those with better outcomes. Taken together with these earlier results, our present findings support the notion of an association of the poor longitudinal outcome with the continued excessive loss of gray matter in patients with chronic schizophrenia.

It may be concluded, that albeit white matter volumes and anisotropy deficits in patients with poor outcome overall grew less conspicuous over time, there was evidence of the widespread illness progression in gray matter, as well as locally in the upper parietal/posterior frontal, retrosplenial cingulate, and occipital white matter in this patient group. Given the role that has lately been accorded to the progressive white matter pathology of the aging brain in concurrent cognitive decline [60], continued white matter disintegration 
in the posterior cerebral regions in the middle-aged pooroutcome schizophrenia patients may in part be responsible for the steep cognitive and functional deterioration documented in these patients some two decades later in life [6163]. Further, it may also reflect the unremitting and treatment-resistant course, characteristic of the Kraepelinian schizophrenia subtype, as compromised anisotropy indices observed during acute psychotic episodes have been shown to improve with treatment response and remission [64]. In contrast, clinical response to antipsychotic treatment (as seen in patients with good outcome) may be associated with deceleration of cortical gray matter loss, not seen in the treatment-resistant poor-outcome patients with schizophrenia.

\section{Illness Severity at Study Entrance and Progressive Brain Changes}

Schizophrenia patients with more severe symptomatology at baseline presentation tended to exhibit greater expansion in regional white matter volumes, as well as greater decline in white matter anisotropy and gray matter volumes over the follow-up period. In particular, schizophrenia patients with more severe negative symptoms at baseline assessment showed greater decline in white matter anisotropy over time in the left orbitofrontal and right upper parietal regions. Schizophrenia patients with more severe general psychopathology at baseline assessment displayed greater expansion in the temporal and occipital white matter volumes and greater reduction in the parietal gray matter volumes. Somewhat similar to our results, Cahn et al. [65] in a longitudinal schizophrenia study found that greater increase in white matter volumes over the first year of follow-up was predictive of higher PANSS positive syndrome subscale scores at 5-year follow-up. In contrast, in a 3-year follow-up study of first-episode schizophrenia patients, those with more severe negative symptoms tended to exhibit a greater reduction in frontal white matter volume [23], which once again suggests that the predominant patterns of volume change may differ at various stages of illness.

\section{Limitations of the Study}

The limitations in this study include the number of participants lost to follow-up and imprecision in Brodmann's area identification. While we retained close to half of our sample, the demographics and initial severity of rescanned or attrited subjects were extremely similar; further, the baseline patient/control differences in morphometric measures were very similar to our earlier reports on the full baseline sample of 145 subjects [40, 41], suggesting that major biases were not involved. Our mapping of the cortical Brodmann's areas was based on microscopic examination of a single brain and thus should be treated as approximation. This is especially pertinent to the underlying white matter, which lacks consensual anatomical landmarks outside fascicles and can be only schematically described in relation to the cortical architectonic map. Our use of multiway ANOVA which combines related areas minimizes regional identification error as a proportion of the effect sizes observed. Lastly, due to the longitudinal design of the study - begun 8 years ago some of the methodology (especially pertinent to the diffusion-tensor imaging) inevitably lagged behind the rapid technical advances in the field. Future longitudinal assess- ments should directly compare larger samples of firstoutbreak and chronic schizophrenia patients, employing newer acquisition techniques with smaller between-slice intervals, making it possible to evaluate changes in individual white matter tracts.

\section{ACKNOWLEDGMENTS}

This work was supported by NIMH grants P50 MH 66392-01, MH 60023, and MH 56489 to Dr. Buchsbaum and by NARSAD Young Investigator Award and NIMH MH 077146 grant to Dr. Mitelman.

\section{REFERENCES}

[1] DeLisi LE. The concept of progressive brain change in schizophrenia: implications for understanding schizophrenia. Schizophr Bull 2008; 34: 312-21.

[2] van Haren NEM, Cahn W, Hulshoff Pol HE, Kahn RE. Schizophrenia as a progressive brain disease. Eur Psychiatry 2008; 23: 245-54.

[3] Lawrie SM, McIntosh AM, Hall J, Owens DGC, Johnstone EC. Brain structure and function changes during the development of schizophrenia: the evidence from studies of subjects at increased risk. Schizophr Bull 2008; 34: 330-40.

[4] Wood SJ, Pantelis C, Velakoulis D, Yücel M, Fornito A, McGorry PD. Progressive changes in the development toward schizophrenia: studies in subjects at increased symptomatic risk. Schizophr Bull 2009; 34: 322-29.

[5] Mathalon DH, Sullivan EV, Lim KO, Pfefferbaum A. Progressive brain volume changes and the clinical course of schizophrenia in men: a longitudinal magnetic resonance imaging study. Arch Gen Psychiatry 2001; 58: 148-57.

[6] Weinberger DR, McClure RK. Neurotoxicity, neuroplasticity, and magnetic resonance imaging morphometry: what is happening in the schizophrenic brain?. Arch Gen Psychiatry 2002; 59: 553-58.

[7] Mathalon D, Rapoport JL, Davis KL, Krystal JH. Neurotoxicity, neuroplasticity, and magnetic resonance imaging morphometry. Arch Gen Psychiatry 2003; 60: 846-48.

[8] Hulshoff Pol HE, Kahn RS. What happens after the first episode?. A review of progressive brain changes in chronically ill patients with schizophrenia. Schizophr Bull 2008; 34: 354-66.

[9] Wozniak JR, Lim KO. Advances in white matter imaging: a review of in vivo magnetic resonance methodologies and their applicability to the study of development and aging. Neurosci Biobehav Rev 2006; 30: 762-74.

[10] Sullivan EV, Pfefferbaum A. Neuroradiological characterization of normal adult ageing. Br J Radiol 2007; 80(2): S99-S108.

[11] Bartzokis G, Beckon M, Lu PH, Nuechterlein KH, Edwards N, Mintz J. Age-related changes in frontal and temporal lobe volumes in men: a magnetic resonance imaging study. Arch Gen Psychiatry 2001; 58: 461-65.

[12] Bartzokis G, Cummings JL, Sultzer D, Henderson VW, Nuechterlein $\mathrm{KH}$, Mintz J. White matter structural integrity in healthy aging adults and patients with Alzeheimer's disease: a magnetic resonance imaging study. Arch Neurol 2003; 60: 393-98.

[13] Sullivan EV, Pfefferbaum A. Diffusion tensor imaging and aging. Neurosci Biobehav Rev 2006; 30: 749-61.

[14] Damoiseaux JS, Smith SM, Witter MP, et al. White matter tract integrity in aging and Alzheimer's disease. Hum Brain Mapp 2009; 30: 1051-9.

[15] Yoon B, Shim Y-S, Lee K-S, Shon Y-M, Yang D-W. Regionspecific changes of cerebral white matter during normal aging: a diffusion-tensor analysis. Archiv Gerontol Geriatr 2008; 47: 12938.

[16] Salat DH, Tuch DS, Hevelone ND, et al. Age-related changes in prefrontal white matter measured by diffusion tensor imaging. Ann NY Acad Sci 2005; 1064: 37-49.

[17] Hugenschmidt CE, Peiffer AM, Kraft RA, et al. Relating imaging indices of white matter integrity and volume in healthy older adults. Cerebr Cortex 2008; 18: 433-42.

[18] Abe O, Yamasue H, Aoki S, et al. Aging in the CNS: comparison of gray/white matter volume and diffusion tensor data. Neurobiol Aging 2006; 29: 102-16. 
[19] DeLisi LE, Sakuma M, Tew W, Kushner M, Hoff AL, Grimson R. Schizophrenia as a chronic active brain process: a study of progressive brain structural change subsequent to the onset of schizophrenia. Psychiatry Res 1997; 74: 129-40.

[20] Lieberman J, Chakos M, Wu H, et al. Longitudinal study of brain morphology in first episode schizophrenia. Biol Psychiatry 2001; 49: 487-99.

[21] Cahn W, Hulshoff-Pol HE, Lems EBTE, et al. Brain volume changes in first-episode schizophrenia. Arch Gen Psychiatry 2002; 59: 1002-10.

[22] Kasai K, Shenton ME, Salisbury DF, et al. Progressive decrease of left Heschl gyrus and planum temporale gray matter volume in first-episode schizophrenia. Arch Gen Psychiatry 2003; 60: 766-75.

[23] Ho B-C, Andreasen NC, Nopoulos P, Arndt S, Magnotta V, Flaum M. Progressive structural brain abnormalities and their relationship to clinical outcome. Arch Gen Psychiatry 2003; 60: 585-94.

[24] Kasai K, Shenton ME, Salisbury DF, et al. Progressive decrease of left superior temporal gyrus gray matter volume in patients with first-episode schizophrenia. Am J Psychiatry 2003; 160: 156-64.

[25] Farrow TFD, Whitford TJ, Williams LM, Gomes L, Harris AWF. Diagnosis-related regional gray matter loss over two years in first episode schizophrenia and bipolar disorder. Biol Psychiatry 2005; 58: 713-23.

[26] Whitford TJ, Grieve SM, Farrow TDF, et al. Progressive grey matter atrophy over the first 2-3 years of illness in first-episode schizophrenial a tensor-based morphometry study. NeuroImage 2006; 32: 511-19.

[27] Salisbury DF, Kuroki N, Kasai K, Shenton ME, McCarley RW. Progressive and interrelated functional and structural evidence of post-onset brain reduction in schizophrenia. Arch Gen Psychiatry 2007; 64: 521-29.

[28] Nakamura M, Salisbury DF, Hirayasu Y, et al. Neocortical gray matter volume in first-episode schizophrenia and first-episode affective psychosis: a cross-sectional and longitudinal MRI study. Biol Psychiatry 2007; 62: 773-83.

[29] Théberge J, Williamson KE, Aoyama N, et al. Longitudinal greymatter and glutamatergic losses in first-episode schizophrenia. Br J Psychiatry 2007; 191: 325-34.

[30] Zipparo L, Whitford TJ, Redoblado-Hodge MA, et al. Investigating the neuropsychological and neuroanatomical changes that occur over the first 2-3 years of illness in patients with first-episode schizophrenia. Prog Neuropsychopharmacol Biol Psychiatry 2008; 32: 531-38.

[31] van Haren NEM, Hulshoff Pol HE, Schnack HG, et al. Focal gray matter changes in schizophrenia across the course of the illness: a 5-year follow-up study. Neuropsychopharmacol 2007; 32: 2057-66.

[32] Wood SJ, Velakoulis D, Smith DJ, et al. A longitudinal study of hippocampal volume in first episode psychosis and chronic schizophrenia. Schizophr Res 2001; 52: 37-46.

[33] DeLisi LE, Hoff AL. Failure to find progressive temporal lobe volume decreases 10 years subsequent to a first episode of schizophrenia. Psychiatry Res 2005; 138: 265-68.

[34] Whitworth AB, Kemmler G, Honeder M, et al. Longitudinal volumetric MRI study in first- and multiple-episode male schizophrenia patients. Psychiatry Res Neuroimaging 2005; 140: 225-37.

[35] van Haren NEM, Hulshoff Pol HE, Schnack HG, et al. Progressive brain volume loss in schizophrenia over the course of the illness: evidence of maturational abnormalities in early adulthood. Biol Psychiatry 2008; 63: 106-13.

[36] Whitford TJ, Grieve SM, Farrow TF, et al. Volumetric white matter abnormalities in first-episode schizophrenia: a longitudinal, tensor-based morphometry study. Am J Psychiatry 2007; 164: 99598.

[37] Mori T, Ohnishi T, Hashimoto R, et al. Progressive changes in white matter integrity in schizophrenia revealed by diffusion tensor imaging. Psychiatry Res Neuroimaging 2007; 154: 133-45.

[38] Friedman JI, Tang CY, Carpenter D, et al. Diffusion tensor imaging findings in first-episode and chronic schizophrenia patients. Am J Psychiatry 2008; 165: 1024-32.

[39] Mitelman SA, Shihabuddin L, Brickman AM, Hazlett EA, Buchsbaum MS. MRI assessment of gray and white matter distribution in Brodmann's areas of the cortex in patients with schizophrenia with good and poor outcomes. Am J Psychiatry 2003; 160: 2154-168.

[40] Mitelman SA, Newmark RE, Torosjan Y, et al. White matter fractional anisotropy and outcome in schizophrenia. Schizophr Res 2006; 87: 138-59.

[41] Mitelman SA, Brickman AM, Shihabuddin L, et al. A comprehensive assessment of gray and white matter volumes and their relationship to outcome and severity in schizophrenia. NeuroImage 2007; 37: 449-62.

[42] Andreasen NC, Flaum M, Arndt S. The comprehensive assessment of symptoms and history (CASH). An instrument for assessing diagnosis and psychopathology. Arch Gen Psychiatry 1992; 49: 615-23.

[43] Keefe RSE, Mohs RC, Losonczy MF, et al. Characteristics of very poor outcome schizophrenia. Am J Psychiatry 1987; 144: 88995.

[44] Keefe RSE, Mohs RC, Davidson M, et al. Kraepelinian schizophrenia: a subgroup of schizophrenia?. Psychopharmacol Bull 1988; 24: 56-61.

[45] Brickman AM, Buchsbaum MS, Shihabuddin L, et al. Thalamus size and outcome in schizophrenia. Schizophr Res 2004; 71: 47384.

[46] Mitelman SA, Brickman AM, Shihabuddin L, Newmark RE, Chu $\mathrm{K}-\mathrm{W}$, Buchsbaum MS. Correlations between MRI-assessed volumes of the thalamus and cortical Brodmann's areas in schizophrenia. Schizophr Res 2005; 75: 265-81.

[47] Mitelman SA, Buchsbaum MS, Brickman AM, Shihabuddin L. Cortical intercorrelations of frontal area volumes in schizophrenia. NeuroImage 2005; 27: 753-70.

[48] Mitelman SA, Shihabuddin L, Brickman AM, Buchsbaum MS. Cortical intercorrelations of temporal area volumes in schizophrenia. Schizophr Res 2005; 76: 207-29.

[49] Brickman AM, Buchsbaum MS, Ivanov Z, et al. Internal capsule size in good-outcome and poor-outcome schizophrenia. J Neuropsychiatry Clin Neurosci 2006; 18: 364-76.

[50] Mitelman SA, Torosjan Y, Newmark RE, et al. Internal capsule, corpus callosum and long associative fibers in good and poor outcome schizophrenia: a diffusion tensor imaging survey. Schizophr Res 2007; 92: 211-24.

[51] Buchsbaum MS, Schoenknecht P, Torosjan Y, et al. Diffusion tensor imaging of frontal lobe white matter tracts in schizophrenia Ann Gen Psychiatry 2007; 5: 19.

[52] Woods RP, Mazziotta JC, Cherry SR. MRI-PET registration with automated algorithm. J Comput Assist Tomogr 1993; 17: 536-46.

[53] Zhang Y, Brady M, Smith S. Segmentation of brain MR images through a hidden Markov random field model and the expectationmaximization algorithm. IEEE Trans Med Imaging 2001; 20: 45 57.

[54] Premkumar P, Fannon D, Kuipers E, Cooke MA, Simmons A, Kumari V. Association between a longer duration of illness, age and lower frontal grey matter volume in schizophrenia. Behav Brain Res 2008; 193: 132-39.

[55] Burke L, Androutsos C, Jogia J, Byrne P, Frangou S. The Maudsley early onset schizophrenia study: the effect of age of onset and illness duration on fronto-parietal gray matter. Eur Psychiatry 2008; 23: 233-36.

[56] Gur RE, Cowell P, Turetsky BI, et al. A follow-up magnetic resonance imaging study of schizophrenia. Arch Gen Psychiatry 1998; 55: 145-52.

[57] Nusbaum AO, Tang CY, Buchsbaum MS, Wei TC, Atlas SW. Regional and global changes in cerebral diffusion with normal aging. Am J Neuroradiol 2001; 22: 136-42.

[58] Jones DK, Catani M, Pierpaoli C, et al. Age effects on diffusion tensor magnetic resonance imaging tractography measures of frontal cortex connections in schizophrenia. Hum Brain Mapp 2006; 27: 230-38.

[59] Davis KL, Buchsbaum MS, Shihabuddin L, et al. Ventricular enlargement in poor-outcome schizophrenia. Biol Psychiatry 1997; 43: 783-93.

[60] Hinman JD, Abraham C. What's behind the decline?. The role of white matter in aging. Neurochem Res 2007; 32: 2023-31.

[61] Harvey PD, Silverman JM, Mohs RC, et al. Cognitive decline in late-life schizophrenia: a longitudinal study of geriatric chronically hospitalized patients. Biol Psychiatry 1999; 45: 32-40. 
[62] Friedman JI, Harvey PD, Coleman T, et al. Six-year follow-up study of cognitive and functional status across the lifespan in schizophrenia: a comparison with Alzheimer's disease and normal aging. Am J Psychiatry 2001; 158: 1441-48.

[63] Mitelman SA, Buchsbaum MS. Very poor outcome schizophrenia: clinical and neuroimaging aspects. Int Rev Psychiatry 2007; 19: $345-57$.
[64] Garver DL, Holcomb JA, Christensen JD. Compromized myelin integrity during psychosis with repair during remission in drugresponding schizophrenia. Int J Neuropsychopharmacol 2008; 11: 49-61.

[65] Cahn W, van Haren NEM, Hulshoff Pol HE, et al. Brain volume changes in the first year of illness and 5-year outcome of schizophrenia. Br J Psychiatry 2006; 189: 381-82.

(C) Mitelman et al.; Licensee Bentham Open.

This is an open access article licensed under the terms of the Creative Commons Attribution Non-Commercial License (http://creativecommons.org/licenses/bync/3.0/) which permits unrestricted, non-commercial use, distribution and reproduction in any medium, provided the work is properly cited. 